Article

\title{
New Approach for Optimal Location and Parameters Setting of UPFC for Enhancing Power Systems Stability under Contingency Analysis
}

\author{
Muhammad Zahid ${ }^{1}{ }^{*}$, Jinfu Chen ${ }^{1}$, Yinhong Li ${ }^{1}$, Xianzhong Duan ${ }^{1}$, Qi Lei ${ }^{1}$, Wang Bo ${ }^{2}$, \\ Ghulam Mohy-ud-din ${ }^{3,4}$ (D) and Asad Waqar 5 \\ 1 School of Electrical and Electronics Engineering, Huazhong University of Science and Technology, \\ Wuhan 430074, China; chenjinfu@mail.hust.edu.cn (J.C.); liyinhong@mail.hust.edu.cn (Y.L.); \\ xzduan@hust.edu.cn (X.D.); qilei@hust.edu.cn (Q.L.) \\ 2 State Grid Hubei Electric Power Company Technology, Project No. 52153816000Y, Wuhan 430074, China; \\ wangb136@hb.sgcc.com.cn \\ 3 School of Electrical, Computer and Telecommunication Engineering, University of Wollongong, \\ Wollongong, NSW 2522, Australia; gmud774@uowmail.edu.au \\ 4 Department of Electrical Engineering, COMSATS Institute of Information Technology, \\ Wah Cantt 47040, Pakistan; ghulammohyuddin@ciitwah.edu.pk \\ 5 Department of Electrical Engineering, Bahria University, Islamabad 44000, Pakistan; \\ asadwaqar.buic@bahria.edu.pk \\ * Correspondence: zahid@hust.edu.cn
}

Received: 13 September 2017; Accepted: 23 October 2017; Published: 30 October 2017

\begin{abstract}
Operation of power system within specified limits of voltage and frequency are the major concerns in power system stability studies. As power system is always prone to disturbances, which consequently affect the voltage instability and optimal power flow, and therefore risks the power systems stability and security. In this paper, a novel technique based on the "Artificial Algae Algorithm" (AAA) is introduced, to identify the optimal location and the parameters setting of Unified Power Flow Controller (UPFC) under N-1 contingency criterion. In the first part, we have carried out a contingency operation and ranking process for the most parlous lines outage contingencies while taking the transmission lines overloading (NOLL) and voltage violation of buses (NVVB) as a performance parameter $(\mathrm{PP}=\mathrm{NOLL}+\mathrm{NVVB})$. As UPFC possesses too much prohibitive cost and larger size, its optimal location and size must be identified before the actual deployment. In the second part, we have applied a novel AAA technique to identify the optimal location and parameters setting of UPFC under the discovered contingencies. The simulations have been executed on IEEE 14 bus and 30 bus networks. The results reveals that the location of UPFC is significantly optimized using AAA technique, which has improved the stability and security of the power system by curtailing the overloaded transmission lines and limiting the voltage violations of buses.
\end{abstract}

Keywords: optimal power flow; Artificial Algae Algorithm (AAA); Unified Power Flow Controller (UPFC); contingency; Performance Parameter (PP)

\section{Introduction}

The demand of efficient and improved quality of electrical energy is presently growing daily. Nowadays, power networks are expected to be efficient and versatile in terms of electric power regulation. It becomes strenuous for the power system to gratify security constraints under all operating circumstances. Normally, the power networks are designed and functioned to fulfill the N-1 security criterion. It means that during first contingencies the power networks should endure in stable condition [1]. However, this $\mathrm{N}-1$ security criterion is expensive and traditionalist. Therefore, to enhance 
the power flow regulation, capacity of transmission lines, to increase the stability and security of power systems, Flexible AC Transmission Systems (FACTS) technology has been developed [2]. The leading role of this technology are voltage regulation, rise power transmission capacity, reduction in heavily loaded lines and improved power system stability. Therefore, this technology is fruitful for improving the power systems stability and security under contingency criterion. Unified Power Flow Controller (UPFC) is the most advanced member of FACTS. UPFC can restrict the parameters of power networks such as voltage magnitude, impedance of line and phase angle simultaneously. It has the capacity to regulate the active power, reactive power, and the voltage of connecting buses [3]. UPFC can be deployed anywhere in the power system and its performance will be varied on different transmission lines. However, to get maximum performance of this device, it is necessary to ascertain the ideal position of UPFC in the power systems and to acquire the proper values of its parameters. Where UPFC should be installed is a serious issue. Some performance measurements must be gratified while deployment of UPFC on optimal location. Different aspects that can be considered in the choice of UPFC location and parameters settings include improvement in power transfer capacity, prevention of power blackout, and increment in power systems stability and security. Therefore, conventional power flow program [4] should be integrated with UPFC and can be considered above any cited factors to be optimized. In this paper, we have considered the improvement in power systems stability and security, by reducing the overloaded transmission lines and improving the voltage profile of buses through optimal placing of UPFC. This operation is conducted under the single line contingency analysis. In the contingency analysis area, a significant development has been achieved by implementing different contingency methods by different researchers [5-7].

In the last few years, many algorithms have been employed to identify the optimal location and parameters setting of the FACTS devices. Particle swarm optimization (PSO) and genetic algorithm (GA) techniques were developed to detect the optimal location of UPFC for improving the power systems security [8]. Differential evaluation (D.E) algorithm was employed to obtain the optimal location and parameter setting of UPFC device for increasing system security during single line contingencies [1,9]. Cat swarm optimization has been used to magnify the voltage stability in an interconnected system under $\mathrm{N}-1$ contingency by identifying the optimal position and rating of UPFC [10]. Application of hybrid group search optimization (HGSO) was tested for improving the power system networks security under N-1 contingencies (line) by optimally placing the UPFC. However, in this study, dynamic aspects of the problem were not considered [11]. To analyze the optimal power flow problem by placing multiple UPFCs while taking active power losses and cost of generation, the gravitational search algorithm (GSA) was applied [12]. Brainstorm optimization algorithm (BSOA) was introduced to check the suitable position of TCSC and SVC devices to manage voltage profile and to reduce the active power losses [13]. In Reference [14], Hybrid immune algorithm (IGA and IPSO) was developed for optimal engagement of UPFC with the motivation of enhancing the power systems loading. These techniques were tested for IEEE 14 and IEEE 30 bus test networks. A meta-heuristic technique (Krill Herd Algorithm) was developed for optimally placing the FACTS device with the objective of power transmission loss minimization [15]. The attributes of some other techniques applied to optimal location of FACTS problems with different objective functions have been also expressed in Table 1. 
Table 1. Some techniques used for optimal location of FACTS problem.

\begin{tabular}{cccc}
\hline Ref. & FACTS Devices & Techniques/Algorithms & Objectives \\
\hline$[16]$ & UPFC & HICA-PS & Voltage Collapse Prevention \\
{$[17]$} & UPFC & ABC, GSA & Improve Dynamic Stability of the System \\
{$[18]$} & SVC, TCSC & RGA & To improve Available Transfer Capability (ATC) \\
{$[19]$} & STATCOM & Fuzzy, GA & Voltage Stability Enhancement \\
{$[20]$} & UPFC & BAT Search Algorithm & Minimize real power losses in power system \\
{$[21]$} & DSTATCOM & IA & Reduce Power loss and improve voltage profile \\
{$[22]$} & UPFC & NSGA-II, CMAES & Increase loadability and total minimize cost of the system \\
{$[23]$} & UPFC & FA, CS & Enhance dynamic stability of the system \\
{$[24]$} & UPFC & TS, EPSO & Improve power transmission capability \\
\hline
\end{tabular}

HICA-PS: Hybrid Imperialist Competitive Algorithm-Pattern Search; ABC: Artificial Bee Colony; GSA: Gravitational Search Algorithm; RGA: Real-code Genetic Algorithm; IA: Immune Algorithm; FA: Firefly Algorithm; CS: Cuckoo Search Algorithm; TS: Tabu search Algorithm; EPSO: Evolutionary Particle Swarm Optimization.

Recently, a novel, robust and intelligence optimization technique "Artificial Algae Algorithm (AAA)" has been developed from the living behaviors of microalgae [25]. For the author's knowledge, the application of the AAA concretely for ideal location of FACTS devices (UPFC) has not tested yet in the research publications. In this paper, the novel and advanced intelligence technique AAA is being implemented to identify the optimal location of UPFC and its parameters setting for improving the power systems stability and security by mitigating voltage violations on buses and reducing or eradicating the overloaded transmission lines under the operation of $\mathrm{N}-1$ security criterion. The performance of this AAA technique is also compared with differential evolution algorithm (D.E) and particle swarm optimization (PSO).

\section{Problem Formulations}

\subsection{UPFC Equivalent Circuit and Power Flow Model}

The UPFC is a device which can regulate all three constraints of transmission line power flow simultaneously (voltage magnitude, angle and line impedance). UPFC is a combination of static synchronous compensator (STATCOM) and static synchronous series compensator (SSSC) [26]. Both converters (STATCOM, SSSC) are aligned via mutual dc link. This composition of circuit permits the real power flow in both directions among the shunt (STATCOM) and series (SSSC) output terminals. This device (UPFC) has capacity of controlling the reactive and active power independently. The UPFC cannot generate or absorb active power, so the active power must be equally shared between two converters (STATCOM, SSSC) by mutual DC link. The voltage of DC link must be controlled to divide this real power uniformly. The equivalent circuit of UPFC is shown in Figure 1. From the equivalent circuit diagram, there are two ideal voltage sources, while $Z_{s h}$ and $Z_{s e}$ are impedances of shunt and series connecting transformers respectively. The two ideal voltage source converters of UPFC can be represents mathematically as [27];

$$
\begin{gathered}
\dot{V}_{s e}=V_{s e}\left(\cos \theta_{s e}+j \sin \theta_{s e}\right) \\
\dot{V}_{s h}=V_{s h}\left(\cos \theta_{s h}+j \sin \theta_{s h}\right)
\end{gathered}
$$

where $V_{s h}$ and $\theta_{s h}$ are voltage magnitude and angle used for shunt voltage source. Similarly, $V_{s e}$ and $\theta_{s e}$ are voltage magnitude and angle with respect to series voltage source. From the equivalent circuit diagram 1, power flow equations with UPFC can be modeled. By using these power flow equations, the power injection at bus $k$ and $m$ can be acquired while including the UPFC. Therefore, power flow equations for this equivalent UPFC model from bus $k$ to bus $m$ are described below [26].

At Bus $k$ :

$$
\begin{aligned}
& P_{k}=V k^{2} G_{k k}+V_{k} V_{m}\left[G_{k m} \cos \left(\theta_{k}-\theta_{m}\right)+B_{k m} \sin \left(\theta_{k}-\theta_{m}\right)\right] \\
& +V_{k} V_{s e}\left[G_{k m} \cos \left(\theta_{k}-\theta_{s e}\right)+B_{k m} \sin \left(\theta_{k}-\theta_{s e}\right)\right]+V_{k} V_{s h}\left[G_{s h} \cos \left(\theta_{k}-\theta_{s h}\right)+B_{s h} \sin \left(\theta_{k}-\theta_{s h}\right)\right]
\end{aligned}
$$


$Q_{k}=-V k^{2} B_{k k}-V_{k} V_{m}\left[G_{k m} \sin \left(\theta_{k}-\theta_{m}\right)-B_{k m} \cos \left(\theta_{k}-\theta_{m}\right)\right]$

$+V_{k} V_{s e}\left[G_{k m} \sin \left(\theta_{k}-\theta_{s e}\right)-B_{k m} \cos \left(\theta_{k}-\theta_{s e}\right)\right]+V_{k} V_{s h}\left[G_{s h} \sin \left(\theta_{k}-\theta_{s h}\right)-B_{s h} \cos \left(\theta_{k}-\theta_{s h}\right)\right]$

At Bus $m$ :

$$
\begin{aligned}
& P_{m}=V m^{2} G_{m m}+V_{m} V_{k}\left[G_{m k} \cos \left(\theta_{m}-\theta_{k}\right)+B_{m k} \sin \left(\theta_{m}-\theta_{k}\right)\right] \\
& \quad+V_{m} V_{s e}\left[G_{m m} \cos \left(\theta_{m}-\theta_{s e}\right)+B_{m m} \sin \left(\theta_{m}-\theta_{s e}\right)\right] \\
& Q_{m}=-V m^{2} B_{m m}+V_{m} V_{k}\left[G_{m k} \sin \left(\theta_{m}-\theta_{k}\right)-B_{m k} \cos \left(\theta_{m}-\theta_{k}\right)\right] \\
& +V_{m} V_{s e}\left[G_{m m} \sin \left(\theta_{m}-\theta_{s e}\right)-B_{m m} \cos \left(\theta_{m}-\theta_{s e}\right)\right]
\end{aligned}
$$

Series converter:

$$
\begin{aligned}
& P_{s e}=V s e^{2} G_{m m}+V_{s e} V_{k}\left[G_{k m} \cos \left(\theta_{s e}-\theta_{k}\right)+B_{k m} \sin \left(\theta_{s e}-\theta_{k}\right)\right] \\
& +V_{s e} V_{m}\left[G_{m m} \cos \left(\theta_{s e}-\theta_{m}\right)+B_{m m} \sin \left(\theta_{s e}-\theta_{k}\right)\right] \\
& Q_{s e}=-V s e^{2} B_{m m}+V_{s e} V_{k}\left[G_{k m} \sin \left(\theta_{s e}-\theta_{k}\right)-B_{k m} \cos \left(\theta_{s e}-\theta_{k}\right)\right] \\
& +V_{s e} V_{m}\left[G_{m m} \sin \left(\theta_{s e}-\theta_{m}\right)-B_{m m} \cos \left(\theta_{s e}-\theta_{k}\right)\right]
\end{aligned}
$$

Shunt converter:

$$
\begin{gathered}
P_{s h}=-V_{s h}^{2} G_{s h}+V_{s h} V_{k}\left[G_{s h} \cos \left(\theta_{s h}-\theta_{k}\right)+B_{s h} \sin \left(\theta_{s h}-\theta_{k}\right)\right] \\
Q_{s h}=V s h^{2} B_{s h}+V_{s h} V_{k}\left[G_{s h} \sin \left(\theta_{s h}-\theta_{k}\right)-B_{s h} \cos \left(\theta_{s h}-\theta_{k}\right)\right]
\end{gathered}
$$

where

$$
\begin{gathered}
Y_{k k}=G_{k k}+j B_{k k} \\
Y_{m m}=G_{m m}+j B_{m m} \\
Y_{k m}=Y_{m k}=G_{k m}+j B_{k m}=\frac{1}{R_{k m}+j X_{k m}}
\end{gathered}
$$

We have assumed here loss-less converter, which means that the active power delivered to shunt converter $P_{s h}$ equivalent to the active power required by the series converter $P_{s e}$.

$$
P_{s h}+P_{s e}=0
$$

The linearized form of UPFC equations, are integrated with the existing AC system network for the condition when UPFC regulates the following parameters: voltage magnitude at bus $k$, reactive power inserted at bus $m$, and active power flow from bus $m$ to bus $k$. Here, bus $m$ is considered to be as a $P Q$ bus. Then, the linearized form of this combination of equations can be written as:

$$
\left[\begin{array}{c}
\Delta P_{k} \\
\Delta P_{m} \\
\Delta Q_{k} \\
\Delta Q_{m} \\
\Delta P_{m k} \\
\Delta Q_{m k} \\
\Delta P_{g g}
\end{array}\right]=\left[\begin{array}{ccccccc}
\frac{\partial P_{k}}{\partial \theta_{k}} & \frac{\partial P_{k}}{\partial \theta_{m}} & \frac{\partial P_{k}}{\partial V_{s h}} V_{s h} & \frac{\partial P_{k}}{\partial V_{m}} V_{m} & \frac{\partial P_{k}}{\partial \theta_{s e}} & \frac{\partial P_{k}}{\partial V_{s e}} \partial V_{s e} & \frac{\partial P_{k}}{\partial \theta_{s h}} \\
\frac{\partial P_{m}}{\partial \theta_{k}} & \frac{\partial P_{m}}{\partial \theta_{m}} & 0 & \frac{\partial P_{m}}{\partial V_{m}} V_{m} & \frac{\partial P_{m}}{\partial \theta_{s e}} & \frac{\partial P_{m}}{\partial V_{s e}} \partial V_{s e} & 0 \\
\frac{\partial Q_{k}}{\partial \theta_{k}} & \frac{\partial Q_{k}}{\partial \theta_{m}} & \frac{\partial Q_{k}}{\partial V_{s h}} V_{s h} & \frac{\partial Q_{k}}{\partial V_{m}} V_{m} & \frac{\partial Q_{k}}{\partial \theta_{s e}} & \frac{\partial Q_{k}}{\partial V_{s e}} \partial V_{s e} & \frac{\partial Q_{k}}{\partial \theta_{s h}} \\
\frac{\partial Q_{m}}{\partial \theta_{k}} & \frac{\partial Q_{m}}{\partial \theta_{m}} & 0 & \frac{\partial Q_{m}}{\partial V_{m}} V_{m} & \frac{\partial Q_{m}}{\partial \theta_{s e}} & \frac{\partial Q_{m}}{\partial V_{s e}} \partial V_{s e} & 0 \\
\frac{\partial P_{m k}}{\partial \theta_{k}} & \frac{\partial P_{m k}}{\partial \theta_{m}} & 0 & \frac{\partial P_{m k}}{\partial V_{m}} V_{m} & \frac{\partial P_{m k}}{\partial \theta_{s e}} & \frac{\partial P_{m k}}{\partial V_{s e}} \partial V_{s e} & 0 \\
\frac{\partial Q_{m k}}{\partial \theta_{k}} & \frac{\partial Q_{m k}}{\partial \theta_{m}} & 0 & \frac{\partial Q_{m k}}{\partial V_{m}} V_{m} & \frac{\partial Q_{m k}}{\partial \theta_{s e}} & \frac{\partial Q_{m k}}{\partial V_{s e}} \partial V_{s e} & 0 \\
\frac{\partial P_{g g}}{\partial \theta_{k}} & \frac{\partial P_{g g}}{\partial \theta_{m}} & \frac{\partial P_{g g}}{\partial V_{s h}} V_{s h} & \frac{\partial P_{g g}}{\partial V_{m}} V_{m} & \frac{\partial P_{g g}}{\partial \theta_{s e}} & \frac{\partial P_{g g}}{\partial V_{s e}} \partial V_{s e} & \frac{\partial P_{g g}}{\partial \theta_{s h}}
\end{array}\right]\left[\begin{array}{c}
\Delta \theta_{k} \\
\Delta \theta_{m} \\
\Delta V_{s h} \\
V_{s h} \\
\frac{\Delta V_{m}}{V_{m}} \\
\Delta \theta_{s e} \\
\Delta V_{s e} \\
V_{s e} \\
\Delta \theta_{s e}
\end{array}\right]
$$

where $\Delta P_{g g}$ represents power mismatch, which is obtained by Equation (14). If the voltage regulation at bus $k$ is disabled, the Equation (15) 3rd column is exchanged by partial derivatives of the bus and mismatch powers of UPFC with respect to the bus voltage magnitude $V_{k}$. Furthermore, the voltage 
magnitude improvement of the parallel voltage source $\left(V_{s h}\right), \Delta V_{s h} / V_{s h}$ is swapped with the voltage magnitude addition at bus $k, \Delta V_{k} / V_{k}$.

The linearized form of equations, if these buses $(k, m)$ are taken as $P Q$ buses can be expressed as:

$$
\left[\begin{array}{c}
\Delta P_{k} \\
\Delta P_{m} \\
\Delta Q_{k} \\
\Delta Q_{m} \\
\Delta P_{m k} \\
\Delta Q_{m k} \\
\Delta P_{g g}
\end{array}\right]=\left[\begin{array}{llllllc}
\frac{\partial P_{k}}{\partial \theta_{k}} & \frac{\partial P_{k}}{\partial \theta_{m}} & \frac{\partial P_{k}}{\partial V_{k}} V_{k} & \frac{\partial P_{k}}{\partial V_{m}} V_{m} & \frac{\partial P_{k}}{\partial \theta_{s e}} & \frac{\partial P_{k}}{\partial V_{s e}} \partial V_{s e} & \frac{\partial P_{k}}{\partial \theta_{s h}} \\
\frac{\partial P_{m}}{\partial \theta_{k}} & \frac{\partial P_{m}}{\partial \theta_{m}} & \frac{\partial P_{m}}{\partial V_{k}} V_{k} & \frac{\partial P_{m}}{\partial V_{m}} V_{m} & \frac{\partial P_{m}}{\partial \theta_{s e}} & \frac{\partial P_{m}}{\partial V_{s e}} \partial V_{s e} & 0 \\
\frac{\partial Q_{k}}{\partial \theta_{k}} & \frac{\partial Q_{k}}{\partial \theta_{m}} & \frac{\partial Q_{k}}{\partial V_{k}} V_{k} & \frac{\partial Q_{k}}{\partial V_{m}} V_{m} & \frac{\partial Q_{k}}{\partial \theta_{s e}} & \frac{\partial Q_{k}}{\partial V_{s e}} \partial V_{s e} & \frac{\partial Q_{k}}{\partial \theta_{s h}} \\
\frac{\partial Q_{m}}{\partial \theta_{k}} & \frac{\partial Q_{m}}{\partial \theta_{m}} & \frac{\partial Q_{m}}{\partial V_{k}} V_{k} & \frac{\partial Q_{m}}{\partial V_{m}} V_{m} & \frac{\partial Q_{m}}{\partial \theta_{s e}} & \frac{\partial Q_{m}}{\partial V_{s e}} \partial V_{s e} & 0 \\
\frac{\partial P_{m k}}{\partial \theta_{k}} & \frac{\partial P_{m k}}{\partial \theta_{m}} & \frac{\partial P_{m k}}{\partial V_{k}} V_{k} & \frac{\partial P_{m k}}{\partial V_{m}} V_{m} & \frac{\partial P_{m k}}{\partial \theta_{s e}} & \frac{\partial P_{m k}}{\partial V_{s e}} \partial V_{s e} & 0 \\
\frac{\partial Q_{m k}}{\partial \theta_{k}} & \frac{\partial Q_{m k}}{\partial \theta_{m}} & \frac{\partial Q_{m k}}{\partial V_{k}} V_{k} & \frac{\partial Q_{m k}}{\partial V_{m}} V_{m} & \frac{\partial Q_{m k}}{\partial \theta_{s e}} & \frac{\partial Q_{m k}}{\partial V_{s e}} \partial V_{s e} & 0 \\
\frac{\partial P_{g g}}{\partial \theta_{k}} & \frac{\partial P_{g g}}{\partial \theta_{m}} & \frac{\partial P_{g g}}{\partial V_{k}} V_{k} & \frac{\partial P_{g g}}{\partial V_{m}} V_{m} & \frac{\partial P_{g g}}{\partial \theta_{s e}} & \frac{\partial g_{g g}}{\partial V_{s e}} \partial V_{s e} & \frac{\partial P_{g g}}{\partial \theta_{s h}}
\end{array}\right]\left[\begin{array}{c}
\Delta \theta_{k} \\
\Delta \theta_{m} \\
\frac{\Delta V_{s h}}{V_{s h}} \\
\frac{\Delta V_{m}}{V_{m}} \\
\Delta \theta_{s e} \\
\frac{\Delta V_{s e}}{V_{s e}} \\
\Delta \theta_{s h}
\end{array}\right]
$$

$V_{s h}$ is preserved at a stable value within recommended limits, $V_{\text {sh min }} \leq V_{s h} \leq V_{\text {sh max }}$. Therefore, the linearized form of Equations (14)-(16), by considering UPFC, can be measured by utilizing the Jacobian matrices (partial derivatives of different elements are referred as Jacobian terms) which are expressed in the above equations.

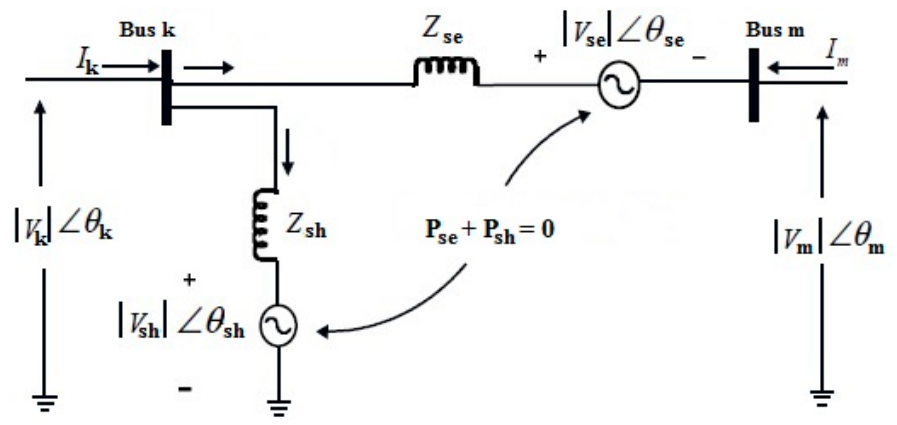

Figure 1. General Equivalent Circuit of UPFC.

\subsection{Contingency Ranking Process}

Contingency analysis strategy is being generally employed to forecast the influence of outage such as malfunctions of equipment, generator, overhead transmission line, etc. [28]. To keep the power system secure and reliable some compulsory actions should be taken if any contingency occurred. Practically, the particular contingencies will generate extreme circumstances in power systems. The method of spotting these dangerous outages is known to as contingency analysis and it can be measured by calculating performance parameters for each transmission line of contingencies. Here, we have considered single transmission line outage as "Performance Parameter" measurement. We identify the number of overloaded transmission lines (NOLL) and voltage violations on buses (NVVB) corresponding to each line of contingency. According to their severity (NOLL + NVVB) for each case, we rank these transmission lines. After completing the contingency analysis for whole system and identifying the most critical transmission lines, AAA is exercised to spot out the optimal location of UPFC with its optimized parameter settings. According to the objective function that is expressed in next segment, the installation of UPFC on optimized location with its parameters setting will eradicate or reduce the voltage violations on buses and overloaded lines under these critical contingency scenarios. 


\subsection{Objective Function}

The fundamental objective of this research is to identify the ideal (effective) location of UPFC and its parameters setting by considering the power systems stability and security improvement. The improvement in power systems stability and security can be secured by eradicating or minimizing voltage violations on different buses and overloaded transmission lines under the most critical single line contingencies.

This optimization problem can be indicated in equation form as:

$$
\operatorname{Min} F(x)=F_{t}(x)
$$

Subject to:

$$
\begin{gathered}
x=\beta \\
G(h, f)=0
\end{gathered}
$$

where

$$
u_{1} \leq L(h) \leq u_{2}
$$

where $F$ denotes the objective vector, $x$ is a decision vector and $\beta$ is the domain of solution. Similarly, $h$ is a vector that stands for the variables of UPFC device, $f$ symbolizes the operating state of power system, $G(h, f)$ corresponds to equality constraints for the active and reactive power balance equations and $L(h)$ is the inequality constraints regarding the UPFC device perimeters (lower and upper limits symbolized by $u_{1}$ and $u_{2}$, respectively). $F_{t}(x)$ expresses the technical criterion to be optimized. Hence, from technical point of view, the UPFC is located at optimal location to remove the overload transmission lines, to share out equal power flows and to eliminate the buses voltage violations. Therefore, we have selected the following technical objective function [1,29]:

$$
F_{t}=\sum_{l=1}^{\mathrm{ntl}} w_{l}\left(\frac{S_{l}}{S_{l \max }}\right)^{2 p}+\sum_{m=1}^{\mathrm{nb}} w_{m}\left(\frac{V_{\text {mref }}-V_{m}}{V_{\text {mref }}}\right)^{2 q}
$$

where ntl is the symbol of "number of transmission lines". $S_{l}$ and $S_{\text {lmax }}$ express the existing apparent power of line $l$ and maximum capacity (MVA) of line $l$. nb representation of "number of buses". $V_{m}$ and $V_{\text {mref }}$ are representing the existing voltage magnitude and reference voltage magnitude of bus $m$, respectively. The $p$ and $q$ are the coefficients which are utilized to compensate more or less the overloaded transmission lines and voltage violations of buses respectively. The proposed value is equal to 2 in our case for these coefficients. The $w_{l}$ and $w_{m}$ are the two weight quantities and decided to have similar index values for $10 \%$ voltage variations and $100 \%$ line loading.

\subsubsection{Equality Constraints}

The break out of transmission lines may leads to power loss of the buses in the power system which might be breakdowns the power balance condition. For this, the important power balance conditions are labeled below to ensure the systems stability and security limits.

For bus $k$ :

$$
\begin{gathered}
P_{k}\left(V_{k}, \theta_{k}\right)+P_{d k}-P_{g k}=0 \\
Q_{k}\left(V_{k}, \theta_{k}\right)+Q_{d k}-Q_{g k}=0
\end{gathered}
$$

For bus $m$ :

$$
\begin{gathered}
P_{m}\left(V_{m}, \theta_{m}\right)+P_{d m}-P_{g m}=0 \\
Q_{m}\left(V_{m}, \theta_{m}\right)+Q_{d m}-Q_{g m}=0
\end{gathered}
$$

where $P_{k}$ and $P_{m}$ are the active powers at bus $k$ and bus $m, Q_{k}$ and $Q_{m}$ are the reactive powers at bus $k$ and bus $m, P_{d k}$ and $Q_{d k}$ are the active and reactive power load at bus $k, P_{d m}$ and $Q_{d m}$ are the active 
and reactive power load at bus $m, P_{g k}$ and $Q_{g k}$ are the active and reactive power generation at bus $k$, and $P_{g m}$ and $Q_{g m}$ are the active and reactive power generation at bus $m$.

For the transmission line where UPFC is connected (let suppose among the line $k$ and $m$ ), $P_{m}$, $Q_{m}, P_{k}$, and $Q_{k}$ can be measured from Equations (3)-(16) by power flow analysis. While for other lines, active and reactive power of buses can be measured by taking the conventional power flow equations [26].

\subsubsection{Inequality Constraints}

The inequality constraints express the working perimeters for physical devices installed in power networks such as generators, transformers and voltage limits on buses, etc.

$$
\begin{aligned}
P_{g k}^{\min } \leq P_{g k} \leq P_{g k}^{\max } \ldots k=1, \ldots, n_{g} \\
Q_{g k}^{\min } \leq Q_{g k} \leq Q_{g k}^{\max } \ldots k=1, \ldots, n_{g} \\
V_{k}^{\min } \leq V_{k} \leq V_{k}^{\max } \ldots k=1, \ldots, n_{b} \\
\theta_{k}^{\min } \leq \theta_{k} \leq \theta_{k}^{\max } \\
V_{s h}^{\min } \leq V_{s h} \leq V_{s h}^{\max } \\
V_{s e}^{\min } \leq V_{s e} \leq V_{s e}^{\max }
\end{aligned}
$$

where $n_{g}$ and $n_{b}$ are the generation buses and set of buses. $V_{k}$ and $\theta_{k}$ are the voltage magnitude and power angle at bus $k . V_{s e}$ and $V_{s h}$ are series and shunt converter voltage magnitudes, respectively.

The following variables are elected to be optimizing in this paper with AAA technique;

- The location of UPFC in the power network is nominated as the first variable of optimization. However, remember that UPFC can be installed on any transmission line excluding where the transformers are already installed on the lines.

- The second variable of optimization by using AAA is parallel voltage source of UPFC. Its operational limits are $[0.9,1.1]$.

- The third variable of optimization is taken as series voltage source of UPFC. Its working array is between $[0.001,0.2]$.

These three variables are examined by using AAA optimization process to advance the power system network stability and security during the single line contingency procedure. The position of UPFC and its parameters setting expressively impact on the power flow in the network during the line contingency process. Therefore, any alteration in these three variables will lead to changes in the power flow of our system. And directly influence on the objective function that is voltage violations of buses and loading of transmission lines.

\section{Optimization using Artificial Algae Algorithm}

\subsection{Overview of $A A A$}

AAA is a novel biologically inspired meta-heuristic optimization algorithm first proposed by Uymaz et al. (2015) [25]. It was established from the motivation of lifestyle of microalgae. These microalgae are photosynthetic species. In this algorithm, population is made of algal colonies. A group of algal cells which are living mutually makes an algal colony. Basically, AAA is the combination of three different processes called "Evolutionary Process", "Adaptation", and the "Helical Movement" [30]. If the algal colony acquires sufficient light, algal cells in algal colonies multiply and propagate to produce two fresh algal cells in $\mathrm{t}$ time same like the real mitotic division. This procedure is called Evolutionary Process. In adaption process, an inadequately grown algal colony seeks to attach it with the biggest algal colony in the surroundings. The third part (Helical Movement) of the 
AAA algorithm algal colonies is updated. Only three algal cells from each population of cluster are adapted and reconstruct in this phase. The movement configuration of algal cells is shown in Figure 2. AAA is an extra efficient, easy, and robust, and only needs few parameters to tune it. This algorithm can be utilized for non-linear problems, non-continuous and non-differentiable space function as well. AAA can also work for time dependent objective functions, multi-dimensional and constraint optimization with penalty utilities. Therefore, by considering these plus points, we elect AAA as optimization technique for the solution of problem which is under measured in this paper.

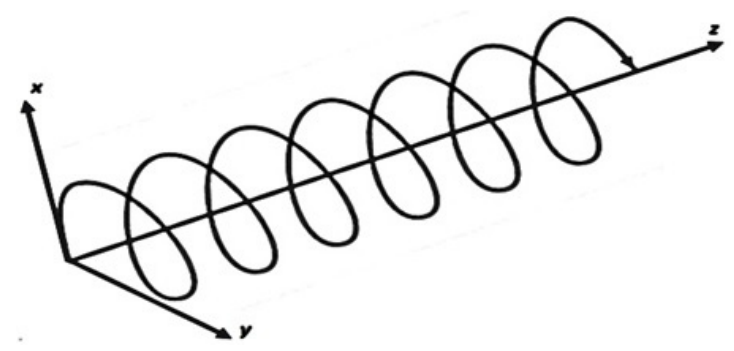

Figure 2. Movement pattern of algal cells.

The general steps or phases of AAA can be explained as follows.

Step 1. Initialize AAA parameters, algal colony $(N)$, maximum fitness evaluations (FEVs), No of dimensions $(D)$ with upper value $(U B)$ and lower value limits $(L B)$, energy loss $(l e)$, adaptation $\left(A_{p}\right)$ and shear force $(\Delta)$.

Step 2. Create initial population randomly of algal colonies in the possible space by using:

$$
x_{i j}=L B_{j}+\left(U B_{j}-L B_{j}\right) \times \text { Randi }=1, \ldots, N ; j=1, \ldots, D
$$

Step 3. Calculate size $(G)$ of algal colonies and fitness of every algal colony by using:

$$
G_{i}^{t+1}=G_{i}^{t}+\left(\mu_{i}^{t} \times G_{i}^{t}\right) i=1,2, \ldots N
$$

where $G_{i}^{t}$ is the size of the $i$ th algal colony in time $t$, and $N$ is total amount algal colonies in system. The growth rate of algal colony can be computed from Monod equation as:

$$
\mu=\frac{\mu_{\max } S}{K_{S}+S}
$$

where $\mu_{\max }$ is the maximum specific growth rate (1/time), $\mathrm{S}$ is the nutrient concentration, and $K_{s}$ is the substrate constant of saturation (mass/volume).

Step 4. This section is very important. This section is iterated until maximum FEVs obtained.

Generate new population by:

i. Helical Movement Phase

In this phase, modify the colony by selecting three algal cells $(k, l$, and $m)$ in the colony arbitrarily.

$$
\begin{gathered}
x_{i m}^{t+1}=x_{i m}^{t}+\left(x_{j m}^{t}-x_{i m}^{t}\right)\left(\Delta-\tau^{t}\left(x_{i}\right)\right) p \\
x_{i k}^{t+1}=x_{i k}^{t}+\left(x_{j k}^{t}-x_{i k}^{t}\right)\left(\Delta-\tau^{t}\left(x_{i}\right)\right) \cos \alpha \\
x_{i l}^{t+1}=x_{i l}^{t}+\left(x_{j l}^{t}-x_{i l}^{t}\right)\left(\Delta-\tau^{t}\left(x_{i}\right)\right) \sin \beta
\end{gathered}
$$

where $x_{i k}^{t}, x_{i l}^{t}$ and $x_{i m}^{t}$ are the $x, y$ and $z$ coordinates of the $i$ th algal cell at time $t ; \Delta$ is the shear force; and $\mathrm{N}$ is the number of algal colonies in the system. Similarly, $\tau^{t}\left(x_{i}\right)$ is the friction surface area of $i$ th algal cell, $\alpha, \beta$ has range $[0,2 \pi]$, and $p$ has limit between $[-1,1]$. 
ii. Reproduction Phase:

Select the biggest and smallest colonies. The biggest algal colony is replicated for each smallest algal colony.

$$
\begin{gathered}
\text { biggest }^{\mathrm{t}}=\max _{i}^{t} i=1,2, \ldots \mathrm{N} \\
\text { smallest }^{\mathrm{t}}=\min _{i}^{t} i=1,2, \ldots \mathrm{N} \\
\text { smallest }_{\mathrm{m}}^{\mathrm{t}}=\text { biggest }_{\mathrm{m}}^{\mathrm{t}} \mathrm{m}=1,2, \ldots \mathrm{D}
\end{gathered}
$$

iii. Adaption Phase:

Select that colony which is most hungry among all colonies.

$$
\text { starving }^{t}=\max _{i}^{\mathrm{t}}, i=1,2, \ldots N
$$

Step 5. Finally, modify the colony by using the equation given below and print the optimal solution.

$$
\text { starving }^{t+1}=\text { starving }^{t}+\left(\text { biggest }^{t}-\text { starving }^{t}\right) \times \text { rand }
$$

Step 6. If the terminating criteria are acquired, then print the best solution.

\subsection{AAA-Based on Optimal Location and Parameters Setting of UPFC}

The load flow analysis of IEEE's standard benchmark systems (IEEE 14 bus, IEEE 30 bus) has been executed by adapting Newton-Raphson (N-R) method [17]. Firstly, investigated the standard load flow analysis of the systems. Then, contingency analysis was performed by outage of the transmission lines one by one by the modified N-R method [26] to identify the performance parameter (PP). Meanwhile, under this state of contingency (a single line outage), AAA method optimizes the location to situate the UPFC based on the objective function, i.e., minimization or removal of overloading of transmission lines and to eradicate the buses voltage violations of the system which were created due to the corresponding line contingency case. The AAA technique acquires the optimal placement of UPFC using the input voltage of buses, angle, and transmission lines losses of the network. The location of UPFC will depends on that transmission line where the objective function ( $\mathrm{PP}=\mathrm{No}$. of overloading lines + voltage violations of buses) is minimized under that contingency scenario. As we have considered that only one line will be tripped off at a time, algorithm will find the optimal location of UPFC with its parameters setting according to each case of contingency.

The step by step approach to optimize the location of UPFC with AAA can be expounded as:

Step 1. Randomly initialize the UPFC parameters $\left(V_{s e}, V_{s h}\right)$ by using Equation (29) to form the initial algae colony for the system.

Step 2. This step is the evaluation of the objective function, and is also called fitness evaluation. For the calculation of objective function or fitness with respect to parameters of Step 1, modified NR load flow analysis is performed as described in Section 2.1. Some other parameters of UPFC $\left(X_{s e}\right.$, $X_{\text {sh }}, V_{\text {se min }}, V_{\text {se max }}, V_{\text {sh min }}, V_{\text {sh max }}, \mathrm{UPFC}_{\text {send }}, \mathrm{UPFC}_{\text {rec }}$, and $V_{\text {sh tar }}$ ) are also included in this process. After calculation of load flow, voltage magnitude of buses and transmission lines loading, generated results are used to calculate the value of objective function or fitness value by using Equation (18) (overloading of transmission lines and voltage violations of buses).

Step 3. Sorting out these generated fitness values, and select the minimum value from these acquired values as a first best algae solution and value.

Step 4. In this step, initial algae colony is updated or modified using the helical movement Equations (32)-(34). After this, the two other operators of AAA algorithm, reproduction and adaptation, are also applied to tune and update the process by Equations (35)-(37) andEquations (38) and (39), respectively. 
Step 5. Repeat Step 2, which is the fitness evaluation (objective function), to update the current algae colony.

Step 6. Repeat Step 3 for finding the second best algae solution and value from the updated algae colony by selecting the minimum value again.

Step 7. Now, first best fitness value of objective function is compared with second best value. If the second value is minimum as compared to first value, then the previous fitness function is replaced by second one and also named as global best value. Otherwise, keep the previous value. It is referred as global best algae and global algae position. Now, again proceed to Step 4 and updated it for the next steps until the stopping criteria are reached.

Step 8. If the stopping criteria (maximum function evaluations/iterations) is fulfilled, then proceed to Step 9 and print the optimum solution (optimal parameters setting $\left(V_{s e}, V_{s h}\right)$ ) for the corresponding contingency case.

Step 9. Abort the program.

When the above procedure is terminated, the scheme is to deliver the optimum location of UPFC and its parameters setting for the corresponding line contingency case. For the best location of UPFC in the power system networks, the position with the minimum objective function is selected. The affected location of UPFC and its parameters were evaluated under the modified N-R program by employing the novel AAA technique.

The flowchart with all procedural steps of this implemented AAA algorithm is expressed in Figure 3.

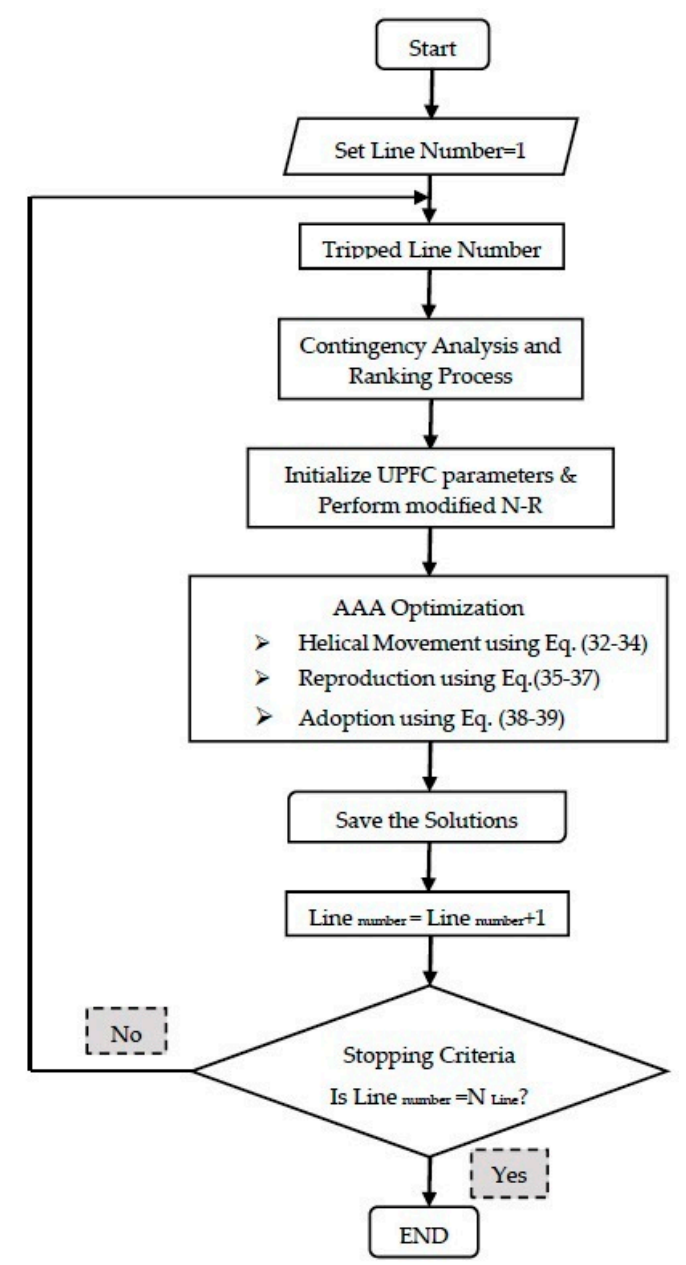

Figure 3. Flowchart AAA-Based on UPFC Location and Parameters Setting. 


\section{Simulations and Results}

\subsection{Case Studies and Simulation Tools}

In this research work, MATLAB programs for AAA and modified N-R power flow algorithm integrated with the UPFC are established for simulation purposes. These simulations are performed using MATLAB 2015a in $2.50 \mathrm{GHz}$, i3, personal computer. The two case studies have been initiated and AAA algorithm is applied on the IEEE's power networks to analyze the effectiveness of the scheme. The two test cases are IEEE 14-bus system and IEEE 30-bus systems. The power systems data of these two case studies are taken from [31-33], respectively. As AAA optimization method is considered stochastic and probabilistic search algorithm, its parameters have no standard values. Here, AAA is implemented on FACTS (UPFC) placement problem for the first time, so we select the AAA parameter ranges according to its best performance. This novel optimization (AAA) method is compared with D.E and PSO techniques to prove the effectiveness. Initial parameters of AAA, D.E and PSO are shown in Table 2.

\subsection{Case Study 1}

The 14-bus test system included 14 buses, 20 transmission lines, five generators, and 11 loads. Firstly, contingency operation and ranking process is applied on 14-bus test network. As there are 20 transmission lines, 20 different line contingency cases will be generated. We will calculate the number of over-loaded transmission lines (NOLL) and the number of voltage violations on buses (NVVB) for each case of contingency to measure the performance parameter. To measure the loading of transmission lines we have considered $100 \%$ loading as standard limit. Voltage violation measurement of buses limit is taken as 0.9 p.u to 1.1 p.u. This analysis provides us the performance parameter $(\mathrm{PP}=\mathrm{NOLL}+\mathrm{NVVB})$ which helps to rank these tripped transmission lines. This ranking operation expressed the severity of line contingencies. The complete operation with performance parameter and ranking process is expressed in Table 3. PP value is zero for normal or undisturbed transmission lines during the line contingency operation. After the completion of this process (Contingency Analysis), we have shortlisted 15 transmission lines that have maximum value of PP or most harsh contingency cases. According to these tripped lines, the maximum overloaded transmission lines and voltage violations on buses will be encountered.

Therefore, to examine the proficiency of UPFC installation on the 14 bus system with respect to each case of contingency, AAA technique is applied to identify the optimal location of UPFC and its parameters setting which relief us in eliminating or minimizing the PP i.e., overloaded transmission lines and bus voltage violations under these critical conditions. This optimization method (AAA) is compared with D.E and PSO techniques to verify the effectiveness. The overloading percentage of transmission lines and voltage violations on buses with respect to each contingency scenario without installing UPFC are exposed in Table 4. We can see that it has 15 contingency cases and, according to each scenario, there have been mentioned overloading percentage of lines and buses voltage limit violations which expose the influence of line contingencies on our power network. Every contingency case has a different impact on transmission lines loading and buses of the system. It should also be noted that, in Table 4, contingency of line 1 is most hazardous as compared to all other cases. It has five overloading of transmission lines and seven buses voltage violations.

In Table 5, it can be analyzed that 11 single line contingencies out of 15 contingency cases on this power network have been successfully removed by using UPFC in the optimal location with its optimized parameters setting acquired by AAA technique. The remaining four contingency scenarios also show the significant improvement in partially reducing the overloading percentage of lines and improving the voltage profile of the buses. Due to the power system structure and the system values, loading percentage of some lines are amplified in some cases. It has been already expressed in Table 4 that many transmission lines overloading percentage was too high that might be source of transmission lines to be tripped off or leads to extreme cascaded disaster and consequently, it could unstable the 
whole power systems. Therefore, after applying UPFC with optimization technique (AAA), the most overloaded transmission lines have been eradicated and the overall power distribution in the rest of the system expressively improved to a level that the power system can endured until some necessary arrangements are to be taken. The optimal locations of UPFC with its optimized parameters setting by implementing AAA, D.E and PSO techniques according to each case of contingency (after 100 trails) are expressed in Table 6.

Table 2. Parameters settings of AAA, D.E and PSO algorithms.

\begin{tabular}{|c|c|c|c|c|c|}
\hline AAA & & D.E [1] & & PSO [1] & \\
\hline Population size (N) & 20 & Population size (NP) & 30 & No. of swarms (NP) & 30 \\
\hline $\begin{array}{l}\text { Max. Fitness Calculation } \\
\text { (MaxFEVs) }\end{array}$ & 100 & $\begin{array}{l}\text { Max. number of } \\
\text { generation (Gmax) }\end{array}$ & 100 & Maximum flights & 100 \\
\hline No. of Dimensions (D) & 2 & No. of variables (NV) & 3 & No. of Variables (NV) & 3 \\
\hline $\begin{array}{l}\text { Maximum value of each } \\
\text { dimension (UB) }\end{array}$ & 2 & Length of individual (Li) & 3 & Length of individual (Li) & 3 \\
\hline Shear force (K) & 2 & DE-step size $(F)$ & 0.5 & $\mathrm{C}_{1}, \mathrm{C}_{2}$ & 1.5 \\
\hline Energy loss (le) & 0.3 & Crossover probability & 0.5 & $\mathrm{w}_{\max }$ & 0.9 \\
\hline Adaptation $\left(\mathrm{A}_{\mathrm{p}}\right)$ & 0.5 & DE strategy & 1 & $\mathrm{w}_{\min }$ & 0.4 \\
\hline \multirow[t]{2}{*}{ Termination criteria } & $1 \times \mathrm{e}^{-6}$ & Termination criteria & $1 \times \mathrm{e}^{-6}$ & Termination Criteria & $1 \times \mathrm{e}^{-6}$ \\
\hline & & & & Deviation of initial velocities & 10 \\
\hline
\end{tabular}

Table 3. Contingency Analysis with Performance Parameter and Ranking Operation.

\begin{tabular}{|c|c|c|c|c|c|c|}
\hline \multicolumn{3}{|c|}{ Tripped Line } & \multirow{2}{*}{$\begin{array}{c}\text { No. of } \\
\text { Over-Loaded } \\
\text { Lines (NOLL) }\end{array}$} & \multirow{2}{*}{$\begin{array}{l}\text { No. of Voltage } \\
\text { Violations on } \\
\text { Buses (NVVB) }\end{array}$} & \multirow{2}{*}{$\begin{array}{c}\text { Performance Parameter } \\
\text { PP = NOLL + NVVB }\end{array}$} & \multirow{2}{*}{ Rank } \\
\hline Line Number & From Bus & To Bus & & & & \\
\hline 1 & 1 & 2 & 5 & 7 & 12 & 1 \\
\hline 3 & 2 & 3 & 4 & 5 & 9 & 2 \\
\hline 2 & 1 & 5 & 2 & 6 & 8 & 3 \\
\hline 10 & 5 & 6 & 1 & 5 & 6 & 4 \\
\hline 4 & 2 & 4 & 2 & 3 & 5 & 5 \\
\hline 14 & 7 & 8 & 0 & 3 & 3 & 6 \\
\hline 15 & 7 & 9 & 1 & 2 & 3 & 7 \\
\hline 13 & 6 & 13 & 1 & 2 & 3 & 8 \\
\hline 5 & 2 & 5 & 0 & 1 & 1 & 9 \\
\hline 7 & 5 & 4 & 0 & 1 & 1 & 10 \\
\hline 8 & 4 & 7 & 0 & 1 & 1 & 11 \\
\hline 9 & 4 & 9 & 0 & 1 & 1 & 12 \\
\hline 16 & 9 & 10 & 0 & 1 & 1 & 13 \\
\hline 17 & 9 & 14 & 0 & 1 & 1 & 14 \\
\hline 20 & 13 & 14 & 0 & 1 & 1 & 15 \\
\hline
\end{tabular}

To examine this procedure more elaborately, we can take transmission line 1 tripped as a model case. From Table 4, it can be analyzed that transmission line 1 was most severe contingency case with maximum voltage violations and highest overloaded of transmission lines percentage. The voltage distribution for the case study 1 with installing UPFC on optimal place with its optimized parameter values by AAA and compared with existing techniques D.E and PSO are exposed in Figure 4 (line 1 tripped off). Figure 4 shows that all voltage violations have been successfully eliminated with optimally placing UPFC by AAA, D.E and PSO techniques. Voltage profile of some buses further improved using AAA as compared to D.E and PSO (Figure 4). The power flow distributions for this case (line 1 tripped) with AAA, D.E and PSO are displayed in Figure 5. It is essential to note that there were five overloaded transmission lines and seven voltage violations on different buses before installing UPFC as given in Table 4. However, after employing UPFC on optimized location with its parameters acquired by AAA, three overloaded transmission lines were completely eradicated, and overloading percentage for remaining lines significantly decreased. As we can see in Table 5, line 2 to 3 overloading percentage reduces to $103.09 \%$ from $191.96 \%$ and line 4 to 5 overloading percentage declines to $102.4 \%$ from 
$170.62 \%$ after employing the UPFC on optimal location. Transmission lines 1 to 5,3 to 4 and 9 to 10 are completely working in normal load conditions, so power flow distribution among the transmission lines became limited and improved in this severe contingency case. The voltage violations of buses 2 , $4,5,6,7,13$, and 14 have been completely eliminated or improved. The optimized location of UPFC is line 3 to 4 by using AAA algorithm for this contingency scenario (line 1 tripped), as exposed Table 6 . If we compare these overloading percentage results with D.E, it can be realized that the overloading of transmission lines 2 to 3 is $110.42 \%, 3$ to 4 is $102.70 \%$ and 4 to 5 is $110.76 \%$. Similarly, by using PSO, the transmission lines overloading for line 1 to 5 is $108.65 \%$, line 2 to 4 is $112.33 \%$ and line 4 to 5 have $138.98 \%$. In addition, the voltage violations of buses are completely removed. We have taken this severe case as a model of the results, which is acquired by using AAA, D.E and PSO due to limited space available in this paper. If we compare the results of these (AAA, D.E and PSO) optimization techniques for this scenario, it can be concluded that AAA performs more efficiently than D.E and PSO in both parts of our objective function. Therefore, it can be verified from this case that, not only the stability and security of the power systems can be restored after line contingencies, but there is also significant improvement in it by placing UPFC optimally. The convergence curve of the objective function by using the AAA, D.E and PSO optimization techniques during line 1 outage has been established in Figure 6. The optimal locations of UPFC with its parameter settings by applying AAA, D.E and PSO corresponding to each case of contingency have been expressed in Table 6.

Table 4. Overloading lines with percentage and bus voltage violations without UPFC.

\begin{tabular}{|c|c|c|c|c|c|c|}
\hline \multicolumn{3}{|c|}{ Tripped Lines } & \multicolumn{4}{|c|}{$\begin{array}{c}\text { Overloaded Lines with Overloading \%, and Voltage Violations of } \\
\text { Buses without UPFC under Contingency Analysis }\end{array}$} \\
\hline \multirow{2}{*}{ Line No } & \multirow{2}{*}{ From Bus } & \multirow{2}{*}{ To Bus } & \multicolumn{2}{|c|}{ Lines } & \multirow{2}{*}{ O.L.L\% } & \multirow{2}{*}{ V.V } \\
\hline & & & From & To & & \\
\hline \multirow{5}{*}{1} & \multirow{5}{*}{1} & \multirow{5}{*}{2} & 1 & 5 & 110.91 & \multirow{5}{*}{$2,4,5,6,7,13,14$} \\
\hline & & & 2 & 3 & 191.96 & \\
\hline & & & 3 & 4 & 189.11 & \\
\hline & & & 4 & 5 & 170.62 & \\
\hline & & & 9 & 10 & 133.14 & \\
\hline \multirow{4}{*}{3} & \multirow{4}{*}{2} & \multirow{4}{*}{3} & 1 & 5 & 119.38 & \multirow{4}{*}{$3,9,10,12,13,14$} \\
\hline & & & 2 & 5 & 135.28 & \\
\hline & & & 3 & 4 & 190.52 & \\
\hline & & & 4 & 5 & 175.41 & \\
\hline \multirow{2}{*}{2} & \multirow{2}{*}{1} & \multirow{2}{*}{5} & 1 & 2 & 142.96 & \multirow{2}{*}{$9,10,11,12,13,14$} \\
\hline & & & 2 & 5 & 163.71 & \\
\hline 10 & 5 & 6 & 4 & 5 & 157.28 & $6,11,12,13,14$ \\
\hline \multirow{3}{*}{4} & \multirow{3}{*}{2} & \multirow{3}{*}{4} & 1 & 5 & 116.82 & \multirow{3}{*}{10,14} \\
\hline & & & 2 & 5 & 135.75 & \\
\hline & & & 4 & 5 & 173.71 & \\
\hline 14 & 7 & 8 & - & - & - & $9,10,14$ \\
\hline 15 & 7 & 9 & - & - & - & $9,10,14$ \\
\hline 13 & 6 & 13 & 12 & 13 & 129.68 & 13,14 \\
\hline 5 & 2 & 5 & 1 & 5 & 119.17 & 14 \\
\hline 7 & 5 & 4 & - & - & - & 14 \\
\hline 8 & 4 & 7 & - & - & - & 14 \\
\hline 9 & 4 & 9 & - & - & - & 14 \\
\hline 16 & 9 & 10 & - & - & - & 10 \\
\hline 17 & 9 & 14 & - & - & - & 14 \\
\hline 20 & 13 & 14 & - & - & - & 14 \\
\hline
\end{tabular}


Table 5. Overloading of lines and voltage violations using UPFC at optimized location by AAA, D.E and PSO.

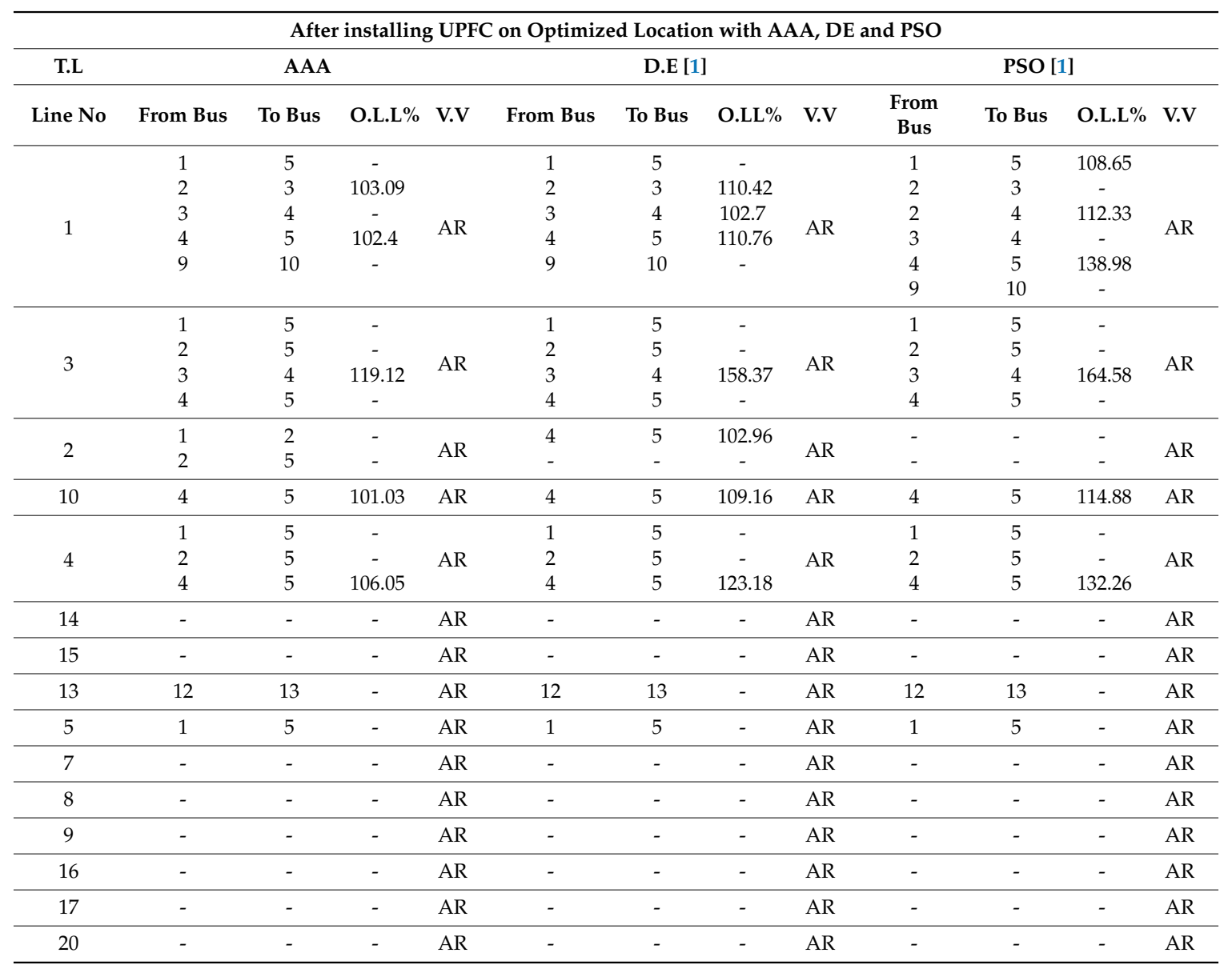

Table 6. Optimal location and parameters setting of UPFC by AAA, D.E and PSO (after 100 trials).

\begin{tabular}{|c|c|c|c|c|c|c|c|c|c|c|c|}
\hline \multicolumn{12}{|c|}{ Optimal Location with Parameters Setting of UPFC by AAA, DE and PSO } \\
\hline \multicolumn{3}{|c|}{ Tripped Lines } & \multicolumn{3}{|c|}{$\begin{array}{l}\text { Location and Parameters } \\
\text { Settings of UPFC by AAA }\end{array}$} & \multicolumn{3}{|c|}{$\begin{array}{l}\text { Location and Parameters } \\
\text { Settings of UPFC by D.E [1] }\end{array}$} & \multicolumn{3}{|c|}{$\begin{array}{l}\text { Location and Parameters } \\
\text { Setting of UPFC by PSO [1] }\end{array}$} \\
\hline No & From & To & Location & $V_{s e}$ & $V_{s h}$ & Location & $V_{s e}$ & $V_{\text {sh }}$ & Location & $V_{s e}$ & $V_{s h}$ \\
\hline 1 & 1 & 2 & $3-4$ & 0.1126 & 1.0073 & 6 & 0.173 & 0.900 & 6 & 0.089 & 1.094 \\
\hline 3 & 2 & 3 & $2-5$ & 0.1154 & 1.050 & 6 & 0.092 & 0.997 & 6 & 0.107 & 1.086 \\
\hline 2 & 1 & 5 & $1-2$ & 0.1233 & 1.0119 & 7 & 0.128 & 1.027 & 7 & 0.029 & 1.059 \\
\hline 10 & 5 & 6 & $4-5$ & 0.0246 & 0.9873 & 19 & 0.045 & 1.019 & 13 & 0.121 & 0.962 \\
\hline 4 & 2 & 4 & $1-5$ & 0.1136 & 1.0246 & 6 & 0.139 & 0.9756 & 6 & 0.119 & 1.082 \\
\hline 14 & 7 & 8 & $3-4$ & 0.0974 & 1.0231 & 6 & 0.108 & 1.065 & 6 & 0.028 & 1.100 \\
\hline 15 & 7 & 9 & $10-14$ & 0.1400 & 1.0318 & 17 & 0.026 & 1.055 & 17 & 0.045 & 0.927 \\
\hline 13 & 6 & 13 & $12-13$ & 0.1166 & 1.0162 & 20 & 0.061 & 1.018 & 20 & 0.090 & 1.012 \\
\hline 5 & 2 & 5 & $1-5$ & 0.1075 & 1.0215 & 20 & 0.036 & 0.927 & 6 & 0.109 & 0.900 \\
\hline 7 & 5 & 4 & $13-14$ & 0.0011 & 1.0409 & 20 & 0.084 & 0.901 & 6 & 0.091 & 0.900 \\
\hline 8 & 4 & 7 & $3-4$ & 0.1139 & 1.0135 & 20 & 0.037 & 0.987 & 6 & 0.046 & 0.9500 \\
\hline 9 & 4 & 9 & $13-14$ & 0.1588 & 1.0078 & 6 & 0.086 & 0.918 & 20 & 0.100 & 0.900 \\
\hline 16 & 9 & 10 & $3-4$ & 0.1140 & 1.0135 & 6 & 0.101 & 0.90 & 6 & 0.079 & 0.900 \\
\hline 17 & 9 & 14 & $3-4$ & 0.1494 & 0.9095 & 6 & 0.056 & 1.022 & 6 & 0.104 & 0.992 \\
\hline 20 & 13 & 14 & $3-4$ & 0.1115 & 1.0250 & 6 & 0.077 & 1.033 & 6 & 0.089 & 1.094 \\
\hline
\end{tabular}




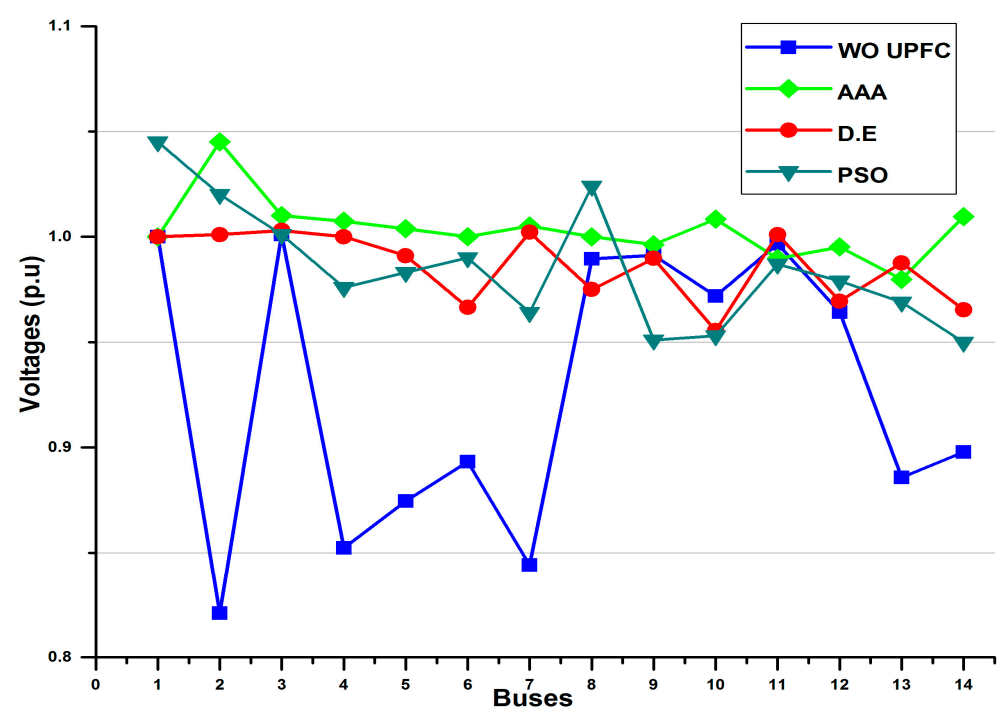

Figure 4. Voltage magnitudes for Case Study-1 by AAA, D.E and PSO when line 1 is trip.

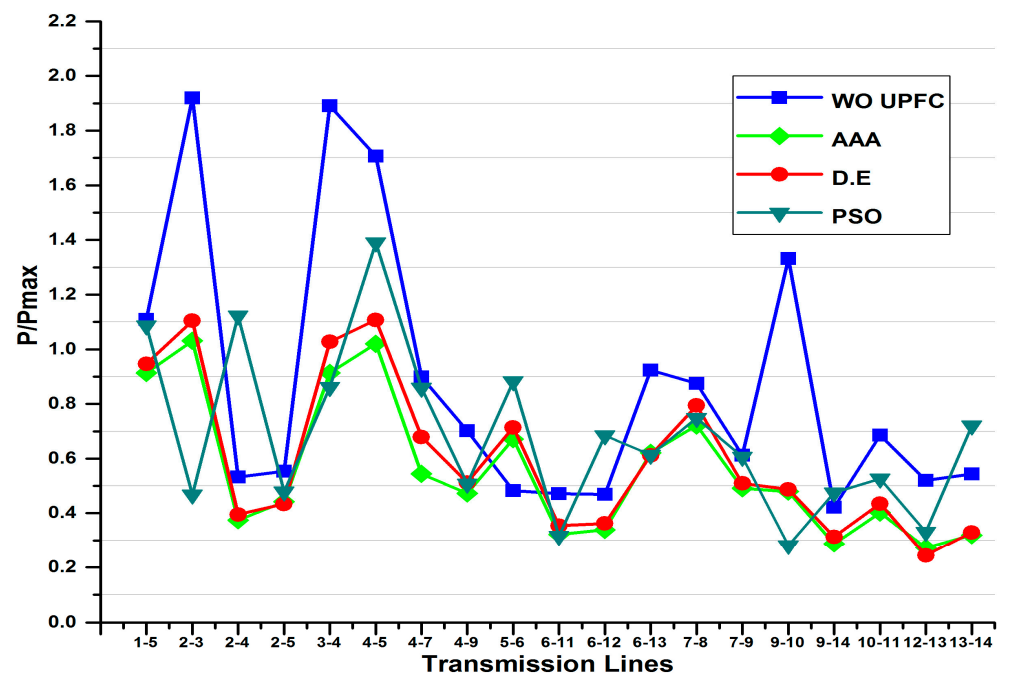

Figure 5. Power Flow distribution for Case Study-1 by AAA, D.E and PSO when line 1 is trip.

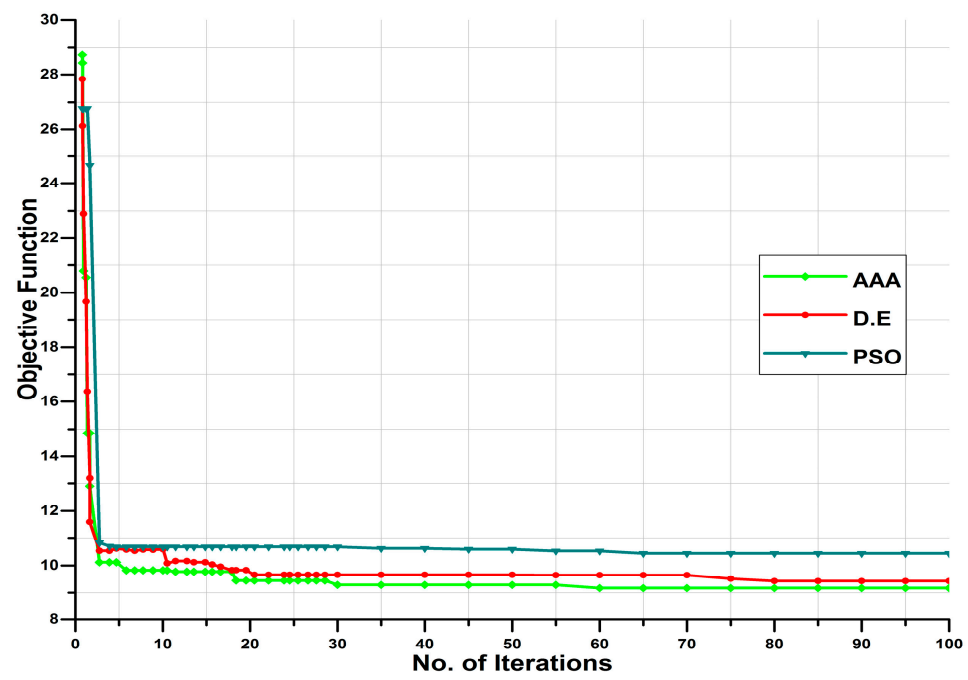

Figure 6. Convergence Curve of the objective function by AAA, D.E and PSO for Case Study-1 (line 1 trip). 


\subsection{Case Study 2}

This IEEE test network contains 30 buses, six generators, 21 loads and 41 transmission lines. Contingency operation executed to complete the ranking process by finding performance parameter on this network. As there are 41 transmission lines, there will likely be 41 single line contingencies. The detailed analysis of contingency operation with ranking and performance parameter PP $=$ (NOLL + NVVB) for severe transmission lines are expressed in Table 7. Performance parameter will be greater than or equal to 1 for disturbed transmission lines. It can be seen that, in Table 7, 23 transmission lines have higher PP, and they are ranked according to each line contingency. To counter these overloaded transmission lines and voltage limit complications of buses, we will discover the optimal location and parameters setting of UPFC corresponding to each case of contingency by AAA technique and compare it with D.E and PSO.

Table 7. Contingency Analysis with Performance Parameter and Ranking Operation.

\begin{tabular}{|c|c|c|c|c|c|c|}
\hline \multicolumn{3}{|c|}{ Tripped Line } & \multirow{2}{*}{$\begin{array}{c}\text { No. of } \\
\text { Overloaded } \\
\text { Lines (NOLL) }\end{array}$} & \multirow{2}{*}{$\begin{array}{l}\text { No. of Voltage } \\
\text { Violations on } \\
\text { Buses (NVVB) }\end{array}$} & \multirow{2}{*}{$\begin{array}{l}\text { Performance Parameter } \\
\text { PP = NOLL + NVVB }\end{array}$} & \multirow{2}{*}{ Rank } \\
\hline Line No & From Bus & To Bus & & & & \\
\hline 1 & 1 & 2 & 9 & 10 & 19 & 1 \\
\hline 14 & 9 & 10 & 4 & 10 & 14 & 2 \\
\hline 18 & 12 & 15 & 1 & 8 & 9 & 3 \\
\hline 10 & 6 & 8 & 2 & 4 & 6 & 4 \\
\hline 2 & 1 & 3 & 4 & 1 & 5 & 5 \\
\hline 3 & 2 & 4 & 5 & 0 & 5 & 6 \\
\hline 22 & 15 & 18 & 2 & 3 & 5 & 7 \\
\hline 6 & 2 & 6 & 4 & 0 & 4 & 8 \\
\hline 8 & 5 & 7 & 3 & 1 & 4 & 9 \\
\hline 5 & 2 & 5 & 3 & 0 & 3 & 10 \\
\hline 11 & 6 & 9 & 3 & 0 & 3 & 11 \\
\hline 20 & 14 & 15 & 2 & 1 & 3 & 12 \\
\hline 25 & 10 & 20 & 0 & 3 & 3 & 13 \\
\hline 35 & 25 & 27 & 1 & 2 & 3 & 14 \\
\hline 36 & 27 & 28 & 0 & 3 & 3 & 15 \\
\hline 4 & 3 & 4 & 2 & 0 & 2 & 16 \\
\hline 29 & 21 & 22 & 2 & 0 & 2 & 17 \\
\hline 37 & 27 & 29 & 0 & 2 & 2 & 18 \\
\hline 38 & 27 & 30 & 1 & 1 & 2 & 19 \\
\hline 19 & 12 & 16 & 1 & 0 & 1 & 20 \\
\hline 21 & 16 & 17 & 1 & 0 & 1 & 21 \\
\hline 23 & 18 & 19 & 0 & 1 & 1 & 22 \\
\hline 24 & 19 & 20 & 0 & 1 & 1 & 23 \\
\hline
\end{tabular}

The complete contingency operation with overloading percentage and voltage violations of buses is revealed in Table 8. It can be seen that the impact is different on the power network with respect to each case of contingency. Twenty-three different contingency scenarios have overloaded transmission lines and voltage limit violations. The extreme severe contingency case among these 23 cases is outage of line 1 , as it has maximum number of voltage violations (10) and overloading of transmission lines (9) with PP equal to 19. However, it can be analyzed in Table 9 that 18 severe transmission line contingencies fully were eradicated by incorporating UPFC optimally with its optimized parameters acquired by optimization technique (AAA). The remaining five contingencies express significant progress in power flow distribution, and minimize lines overloading percentage and voltage profile improvement while using UPFC on optimized location. It is also analyzed that all buses voltage violation for 23 contingencies scenarios are eliminated successfully (Table 9). These results are obtained using AAA and compared with D.E and PSO techniques. The complete effect of UPFC placement with AAA, D.E and PSO according to every case of contingency is addressed in Table 9. 
Table 8. Overloading lines with percentage and bus voltage violations without UPFC.

\begin{tabular}{|c|c|c|c|c|c|c|}
\hline \multicolumn{3}{|c|}{ Tripped Lines } & \multicolumn{4}{|c|}{$\begin{array}{c}\text { Overloaded Lines with Overloading \%, and Voltage Violations of } \\
\text { Buses without UPFC under Contingency Analysis }\end{array}$} \\
\hline \multirow{2}{*}{ Line No } & \multirow{2}{*}{ From Bus } & \multirow{2}{*}{ To Bus } & \multicolumn{2}{|c|}{ Lines } & \multirow{2}{*}{ O.L.L\% } & \multirow{2}{*}{ V.V } \\
\hline & & & From & To & & \\
\hline \multirow{9}{*}{1} & \multirow{9}{*}{1} & \multirow{9}{*}{2} & 1 & 3 & 179.2 & \multirow{9}{*}{$2,3,4,6,7,9,12,13,14,15$} \\
\hline & & & 2 & 4 & 162.8 & \\
\hline & & & 3 & 4 & 176.2 & \\
\hline & & & 2 & 5 & 146.9 & \\
\hline & & & 2 & 6 & 142.3 & \\
\hline & & & 4 & 6 & 137.5 & \\
\hline & & & 5 & 7 & 158.1 & \\
\hline & & & 6 & 8 & 119.4 & \\
\hline & & & 8 & 28 & 107.8 & \\
\hline \multirow{4}{*}{14} & \multirow{4}{*}{9} & \multirow{4}{*}{10} & 6 & 10 & 117.67 & $10,16,17$ \\
\hline & & & 4 & 12 & 125.97 & $18,20,21$ \\
\hline & & & 10 & 17 & 119.53 & $19,22,24$ \\
\hline & & & 25 & 26 & 153.49 & 26 \\
\hline 18 & 12 & 15 & 10 & 17 & 157.48 & $14,15,18,19,20,23,24,26$ \\
\hline \multirow[b]{2}{*}{10} & \multirow{2}{*}{6} & & 8 & 28 & 182.85 & 25,26 \\
\hline & & 8 & 6 & 28 & 175.4 & 29,30 \\
\hline & & & 1 & 2 & 143.65 & \\
\hline & & & 2 & 4 & 135.07 & \\
\hline 2 & 1 & 3 & 2 & 6 & 114.37 & 3 \\
\hline & & & 5 & 7 & 105.30 & \\
\hline & & & 1 & 3 & 137.14 & \\
\hline & & & 3 & 4 & 122.10 & \\
\hline 3 & 2 & 4 & 2 & 6 & 157.09 & No Violations \\
\hline & & & 4 & 6 & 111.73 & \\
\hline & & & 5 & 7 & 123.41 & \\
\hline & & & 19 & 20 & 105.09 & \\
\hline 22 & 15 & 18 & 10 & 20 & 123.41 & $18,19,20$ \\
\hline & & & 1 & 3 & 116.72 & \\
\hline & & & 2 & 4 & 146.94 & \\
\hline 6 & 2 & 6 & 4 & 6 & 158.00 & No Violations \\
\hline & & & 5 & 7 & 118.95 & \\
\hline & & & 1 & 3 & 120.22 & \\
\hline 8 & 5 & 7 & 2 & 4 & 111.38 & 7 \\
\hline & & & 2 & 6 & 103.56 & \\
\hline & & & 1 & 3 & 139.61 & \\
\hline 5 & 2 & 5 & 2 & 4 & 136.13 & No Violations \\
\hline & & & 2 & 6 & 108.97 & \\
\hline & & & 6 & 10 & 125.49 & \\
\hline 11 & 6 & 9 & 4 & 12 & 118.10 & No Violations \\
\hline & & & 10 & 17 & 114.03 & \\
\hline & & & 15 & 23 & 129.27 & \\
\hline 20 & 14 & 15 & 10 & 17 & 131.99 & 14 \\
\hline 25 & 10 & 20 & - & - & - & $18,19,20$ \\
\hline 35 & 25 & 27 & 6 & 28 & 139.52 & 25,26 \\
\hline 36 & 27 & 28 & - & - & - & $26,29,30$ \\
\hline & & & 1 & 2 & 127.03 & \\
\hline 4 & 3 & 4 & 2 & 4 & 121.20 & No Violations \\
\hline & & & 10 & 21 & 147.33 & \\
\hline 29 & 21 & 22 & 10 & 22 & 176.58 & No Violations \\
\hline 37 & 27 & 29 & - & - & - & 29,30 \\
\hline 38 & 27 & 30 & 29 & 30 & 119.75 & 30 \\
\hline 19 & 12 & 16 & 10 & 17 & 139.98 & No Violations \\
\hline 21 & 16 & 17 & 10 & 17 & 144.92 & No Violations \\
\hline 23 & 18 & 19 & - & - & - & 19 \\
\hline 24 & 19 & 20 & - & - & - & 19 \\
\hline
\end{tabular}


Table 9. Overloading of lines and voltage violations using UPFC at optimized location by AAA, D.E and PSO.

\begin{tabular}{|c|c|c|c|c|c|c|c|c|c|c|c|c|}
\hline \multicolumn{13}{|c|}{ After installing UPFC on Optimized Location with AAA, DE and PSO } \\
\hline \multirow{2}{*}{$\begin{array}{c}\text { T.L } \\
\text { Line No }\end{array}$} & \multicolumn{4}{|c|}{ AAA } & \multicolumn{4}{|c|}{ D.E [1] } & \multicolumn{4}{|c|}{ PSO [1] } \\
\hline & From Bus & To Bus & O.L.L\% & V.V & From Bus & To Bus & O.LL \% & V.V & From Bus & To Bus & O.L.L\% & V.V \\
\hline \multirow{9}{*}{1} & 1 & 3 & - & \multirow{9}{*}{$\mathrm{AR}$} & 1 & 3 & 103.2 & \multirow{9}{*}{ AR } & 1 & 3 & - & \multirow{9}{*}{$\mathrm{AR}$} \\
\hline & 2 & 4 & 108.08 & & 2 & 4 & 129.63 & & 2 & 4 & 148.62 & \\
\hline & 3 & 4 & 103.08 & & 6 & 7 & 127.21 & & 6 & 7 & 116.32 & \\
\hline & 2 & 5 & - & & 2 & 5 & - & & 2 & 5 & - & \\
\hline & 2 & 6 & - & & 2 & 6 & - & & 2 & 6 & 109.51 & \\
\hline & 4 & 6 & - & & 4 & 6 & - & & 4 & 6 & - & \\
\hline & 5 & 7 & - & & 5 & 7 & - & & 6 & 8 & - & \\
\hline & 6 & 8 & - & & 6 & 8 & - & & 6 & 28 & 112.2 & \\
\hline & 8 & 28 & - & & 8 & 28 & - & & 8 & 28 & - & \\
\hline \multirow{4}{*}{14} & 6 & 10 & - & \multirow{4}{*}{$\mathrm{AR}$} & 6 & 10 & - & \multirow{4}{*}{ AR } & 6 & 10 & - & \multirow{4}{*}{$\mathrm{AR}$} \\
\hline & 4 & 12 & - & & 2 & 6 & 115.97 & & 10 & 17 & 109.01 & \\
\hline & 10 & 17 & - & & 10 & 20 & 127.7 & & 23 & 24 & 116.8 & \\
\hline & 25 & 26 & 113.04 & & 25 & 26 & - & & 25 & 26 & 107.2 & \\
\hline 18 & 10 & 17 & - & $\mathrm{AR}$ & 10 & 17 & - & $\mathrm{AR}$ & 10 & 17 & - & $\mathrm{AR}$ \\
\hline \multirow{2}{*}{10} & 8 & 28 & - & & 8 & 28 & - & & 8 & 28 & - & \\
\hline & 6 & 28 & - & AR & 6 & 28 & - & AR & 6 & 28 & - & AR \\
\hline & 1 & 2 & 101.02 & & 1 & 2 & - & & 1 & 2 & - & \\
\hline & 2 & 4 & - & & 2 & 4 & 103.4 & & 2 & 4 & 125.46 & \\
\hline 2 & 2 & 6 & - & AR & 2 & 6 & - & AR & 2 & 6 & - & AR \\
\hline & 5 & 7 & - & & 5 & 7 & - & & 5 & 7 & - & \\
\hline & 1 & 3 & - & & 1 & 3 & 107.77 & & 1 & 3 & 106.53 & \\
\hline & 3 & 4 & - & & 3 & 4 & - & & 3 & 4 & - & \\
\hline 3 & 2 & 6 & 102.7 & $\mathrm{AR}$ & 2 & 6 & 109.37 & $\mathrm{AR}$ & 2 & 6 & 127.17 & AR \\
\hline & 4 & 6 & - & & 4 & 6 & - & & 4 & 6 & - & \\
\hline & 5 & 7 & - & & 5 & 7 & - & & 5 & 7 & - & \\
\hline & 19 & 20 & - & & 19 & 20 & - & & 19 & 20 & - & \\
\hline 22 & 10 & 20 & - & $\mathrm{AR}$ & 10 & 20 & - & AR & 10 & 20 & - & AR \\
\hline & 1 & 3 & - & & 1 & 3 & 107 & & 1 & 3 & 107.82 & \\
\hline & 2 & 4 & - & & 2 & 4 & - & & 2 & 4 & - & \\
\hline 6 & 4 & 6 & 104.5 & AR & 4 & 6 & - & AR & 4 & 6 & 110.45 & AR \\
\hline & 5 & 7 & - & & 5 & 7 & - & & 5 & 7 & - & \\
\hline & 1 & 3 & - & & 1 & 3 & - & & 1 & 3 & - & \\
\hline 8 & 2 & 4 & - & $\mathrm{AR}$ & 2 & 4 & - & AR & 2 & 4 & - & AR \\
\hline & 2 & 6 & - & & 2 & 6 & - & & 2 & 6 & - & \\
\hline & 1 & 3 & - & & 1 & 3 & - & & 1 & 3 & - & \\
\hline 5 & 2 & 4 & - & AR & 2 & 4 & - & AR & 2 & 4 & - & AR \\
\hline & 2 & 6 & - & & 2 & 6 & - & & 2 & 6 & - & \\
\hline & 6 & 10 & - & & 6 & 10 & - & & 6 & 10 & & \\
\hline 11 & 4 & 12 & - & $\mathrm{AR}$ & 4 & 12 & - & $\mathrm{AR}$ & 4 & 12 & - & AR \\
\hline & 10 & 17 & - & & 10 & 17 & - & & 10 & 17 & & \\
\hline & 15 & 23 & - & & 15 & 23 & - & & 15 & 23 & - & \\
\hline 20 & 10 & 17 & - & AR & 10 & 17 & - & AR & 10 & 17 & - & AR \\
\hline 25 & - & - & - & $\mathrm{AR}$ & - & - & - & $\mathrm{AR}$ & - & - & - & $\mathrm{AR}$ \\
\hline 35 & 6 & 28 & - & $\mathrm{AR}$ & 6 & 28 & - & AR & 6 & 28 & - & AR \\
\hline 36 & - & - & - & $\mathrm{AR}$ & - & - & - & $\mathrm{AR}$ & - & - & - & $\mathrm{AR}$ \\
\hline & 1 & 2 & - & & 1 & 2 & - & & 1 & 2 & - & \\
\hline 4 & 2 & 4 & - & AR & 2 & 4 & - & AR & 2 & 4 & - & AR \\
\hline & 10 & 21 & - & & 10 & 21 & - & & 10 & 21 & - & \\
\hline 29 & 10 & 22 & - & AR & 10 & 22 & - & AR & 10 & 22 & - & AR \\
\hline 37 & - & - & - & $\mathrm{AR}$ & - & - & - & $\mathrm{AR}$ & - & - & - & AR \\
\hline 38 & 29 & 30 & - & $\mathrm{AR}$ & 29 & 30 & - & $\mathrm{AR}$ & 29 & 30 & - & AR \\
\hline 19 & 10 & 17 & - & $\mathrm{AR}$ & 10 & 17 & - & $\mathrm{AR}$ & 10 & 17 & - & AR \\
\hline 21 & 10 & 17 & - & $\mathrm{AR}$ & 10 & 17 & - & $\mathrm{AR}$ & 10 & 17 & - & $\mathrm{AR}$ \\
\hline 23 & - & - & - & AR & - & - & - & AR & - & - & - & AR \\
\hline 24 & - & - & - & $\mathrm{AR}$ & - & - & - & $\mathrm{AR}$ & - & - & - & AR \\
\hline
\end{tabular}

We can take line 1 outage as model example here for more explanation of this AAA technique. The voltage profile for 30 bus system with AAA, D.E, and PSO (in the case of transmission line 
1 tripped) have been established in Figure 7. The voltage violations on 10 different buses are not only removed, but also there is significant improvement in voltage magnitude of buses by using AAA technique as given in Figure 7. The power flow distribution among transmission network acquired by AAA, D.E and PSO when line 1 was tripped (most severe case of contingency analysis) have been presented in Figure 8. As we can see from contingency analysis for IEEE 30-bus systems (Table 8), there were 9 overloaded transmission lines and 10 voltage violations on different buses before installing UPFC when line 1 was tripped. However, after obtaining optimal location of UPFC by AAA, seven overloaded transmission lines are fully eradicated and voltage violations on all 10 buses were completely recovered or improved, as shown in Table 9. In addition, the power flow distribution is significantly improved for this scenario. It can be analyzed from Table 9 that, while employing AAA algorithm, the overloading percentage of line 2 to 4 declines up to $108.08 \%$ from $162.8 \%$ and overloading percentage of line 3 to 4 decreases to $103.08 \%$ from $176.20 \%$ after placing the UPFC on optimal location in this contingency case (line 1 tripped). Remaining overloaded transmission lines completely working under normal or underload conditions. The optimal location of UPFC is line 2 to 5 for this particular line contingency case. The voltage violations of buses $(2,3,4,6,7,9,12,13$, 14 , and 15) have been completely eliminated. However, after placing UPFC with D.E, it can be seen that the overloading percentage of line 1 to 3 is $103.2 \%$, line 2 to 4 is $129.63 \%$ and 6 to 7 is $127.21 \%$. The remaining six overloaded transmission lines were completely removed with D.E. Similarly, in the case of PSO, the overloading percentage of lines 2 to 4 is $148.62 \%$, line 6 to 7 is $116.32 \%$, line 2 to 6 is $109.51 \%$, and line 6 to 28 is $112.2 \%$. In this paper, we select only this case (line 1 tripped) as a model of the results we have gained because it is the most severe contingency case and paper space is limited. If we compare these results, it can be concluded that AAA generated the most efficacious, consistent and balanced solutions over other algorithms (D.E and PSO). The convergence characterizations of the objective function using AAA, D.E and PSO optimization techniques during line 1 outage are labeled in Figure 9. The optimal locations of UPFC with its parameters setting $\left(V_{s e}\right.$ and $\left.V_{s h}\right)$, according to each case of contingency (23 cases) are expressed in Table 10.

Table 10. Optimal Location and Parameters setting of UPFC by AAA, D.E and PSO (after 100 trials).

\begin{tabular}{|c|c|c|c|c|c|c|c|c|c|c|c|}
\hline \multicolumn{12}{|c|}{ Optimal Location and Parameters Setting of UPFC by AAA, DE and PSO } \\
\hline \multicolumn{3}{|c|}{ Tripped Lines } & \multicolumn{3}{|c|}{$\begin{array}{l}\text { Location and Parameters } \\
\text { Settings of UPFC by AAA }\end{array}$} & \multicolumn{3}{|c|}{$\begin{array}{l}\text { Location and Parameters } \\
\text { Settings of UPFC by D.E [1] }\end{array}$} & \multicolumn{3}{|c|}{$\begin{array}{l}\text { Location and Parameters } \\
\text { Setting of UPFC by PSO [1] }\end{array}$} \\
\hline No & From & To & Location & $V_{\text {se }}$ & $V_{\text {sh }}$ & Location & $V_{\text {se }}$ & $V_{\text {sh }}$ & Location & $V_{\text {se }}$ & $V_{\text {sh }}$ \\
\hline 1 & 1 & 2 & $2-5$ & 0.0986 & 0.9893 & 7 & 0.115 & 1.100 & 7 & 0.120 & 0.946 \\
\hline 14 & 9 & 10 & $6-10$ & 0.0349 & 0.9305 & 25 & 0.012 & 1.066 & 25 & 0.007 & 1.010 \\
\hline 18 & 12 & 15 & $4-6$ & 0.0010 & 1.0468 & 7 & 0.154 & 0.937 & 7 & 0.079 & 1.034 \\
\hline 10 & 6 & 8 & $10-17$ & 0.0191 & 1.0283 & 27 & 0.118 & 0.969 & 27 & 0.046 & 0.978 \\
\hline 2 & 1 & 3 & $5-7$ & 0.0026 & 1.0295 & 4 & 0.088 & 1.082 & 4 & 0.104 & 1.034 \\
\hline 3 & 2 & 4 & $4-6$ & 0.0460 & 0.9988 & 4 & 0.123 & 1.007 & 4 & 0.087 & 0.991 \\
\hline 22 & 15 & 18 & $6-7$ & 0.0210 & 1.0188 & 9 & 0.061 & 1.077 & 9 & 0.127 & 0.996 \\
\hline 6 & 2 & 6 & $2-4$ & 0.0184 & 1.0842 & 7 & 0.091 & 0.948 & 7 & 0.035 & 1.022 \\
\hline 8 & 5 & 7 & $2-4$ & 0.0157 & 1.0263 & 32 & 0.105 & 1.077 & 32 & 0.106 & 0.998 \\
\hline 5 & 2 & 5 & $2-6$ & 0.0286 & 1.0807 & 4 & 0.049 & 1.022 & 4 & 0.054 & 0.957 \\
\hline 11 & 6 & 9 & $10-17$ & 0.0436 & 0.9934 & 27 & 0.127 & 0.965 & 27 & 0.107 & 1.048 \\
\hline 20 & 14 & 15 & $6-7$ & 0.0543 & 1.0183 & 7 & 0.077 & 1.015 & 7 & 0.066 & 0.976 \\
\hline 25 & 10 & 20 & $4-6$ & 0.0393 & 0.9420 & 7 & 0.104 & 0.998 & 7 & 0.028 & 0.998 \\
\hline 35 & 25 & 27 & $10-21$ & 0.0361 & 0.9745 & 30 & 0.022 & 0.948 & 30 & 0.0063 & 0.948 \\
\hline 36 & 27 & 28 & $14-15$ & 0.0145 & 0.9866 & 20 & 0.048 & 0.911 & 20 & 0.119 & 1.066 \\
\hline 4 & 3 & 4 & $4-12$ & 0.0407 & 1.1000 & 17 & 0.107 & 1.054 & 17 & 0.124 & 0.939 \\
\hline 29 & 21 & 22 & $10-20$ & 0.0697 & 0.9557 & 23 & 0.066 & 0.927 & 23 & 0.098 & 0.922 \\
\hline 37 & 27 & 29 & $4-6$ & 0.0468 & 1.0461 & 7 & 0.091 & 0.920 & 7 & 0.106 & 1.038 \\
\hline 38 & 27 & 30 & $23-24$ & 0.0011 & 1.0522 & 25 & 0.146 & 0.952 & 25 & 0.047 & 0.996 \\
\hline 19 & 12 & 16 & $10-17$ & 0.0312 & 0.9403 & 21 & 0.027 & 1.019 & 21 & 0.059 & 1.042 \\
\hline 21 & 16 & 17 & $15-23$ & 0.0108 & 1.0217 & 30 & 0.125 & 0.993 & 30 & 0.107 & 0.968 \\
\hline 23 & 18 & 19 & $6-7$ & 0.1607 & 0.9345 & 9 & 0.113 & 0.987 & 9 & 0.146 & 1.059 \\
\hline 24 & 19 & 20 & $6-7$ & 0.0879 & 1.0303 & 9 & 0.098 & 0.984 & 9 & 0.076 & 0.997 \\
\hline
\end{tabular}




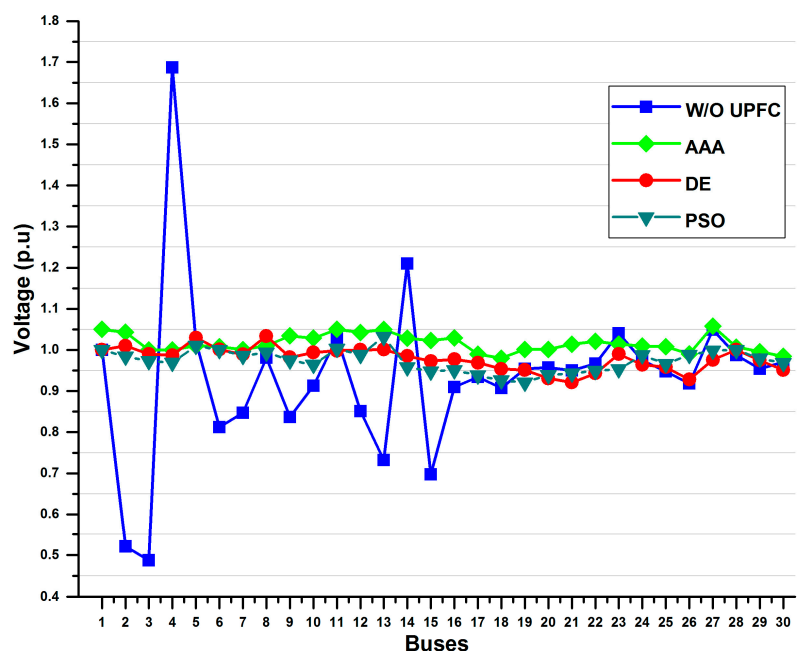

Figure 7. Voltage magnitudes for Case Study-2 by AAA, D.E and PSO when line 1 is trip.

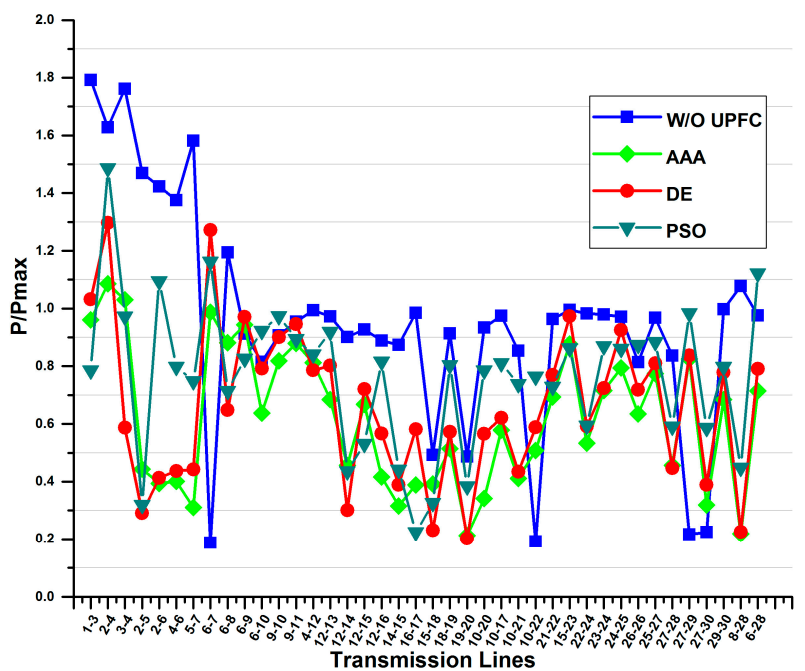

Figure 8. Power Flow distribution for Case Study-2 by AAA, D.E and PSO when line 1 is trip.

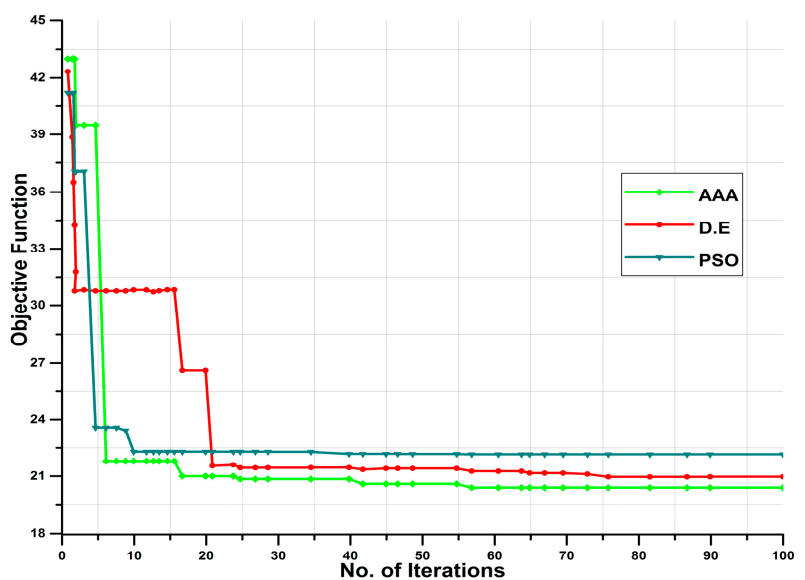

Figure 9. Convergence Curve of the objective function by AAA, D.E and PSO for Case Study-2 (line 1 trip). 


\section{Conclusions}

In this research work, the efficacy of the optimal location of UPFC and its parameter setting has been examined to upgrade the stability and security of the system using AAA under the contingency analysis. The proposed work was divided into two phases. In first phase, contingency analysis was performed to acquire the performance parameter (PP) and ranking process. The performance parameters basically belong to the number of overloaded transmission lines (NOLL) and voltage violations on buses (NVVB) with respect to each line of contingency. We have ranked each line outage contingency case according to their severity and performance parameter value. After this analysis, the novel and advanced intelligence technique AAA was successfully employed to detect the optimal location of UPFC issue. The multi-objective optimization task was to improve the power systems stability and security. The stability and security of the power systems has been significantly improved by reducing the performance parameter value, i.e., by minimizing or eliminating the overloading of transmission lines and voltage violations of buses. To test this latest technique (AAA), two case studies were established by considering IEEE 14 bus system and IEEE 30 bus systems. The acquired solutions prove that the AAA has advanced specifications with accurate, balance characteristics, excellent quality of solution and best computation efficiency. This remarkable effort shows that optimal position of UPFC with its best parameters setting can definitely enhance the stability and security of power systems under $\mathrm{N}-1$ line contingencies.

Acknowledgments: The authors have gratefully acknowledged the State Key Laboratory of Advanced Electromagnetic Engineering and Technology, Huazhong University of Science \& Technology for providing necessary facilities. This work was also supported by Transmission Grid Planning Department, State Grid Hubei Electric Power Company, Economic \& Technology Research Institute. The authors would like to give special thanks to the China Scholarship Council and Higher Education Commission (HEC) Pakistan for providing this opportunity.

Author Contributions: All authors have contributed to this research work. Muhammad Zahid, Jinfu Chen, Yinhong Li, and Xianzhong Duan developed the research framework, analyzed the results and prepared the manuscript. Wang Bo, Qi Lei, Asad Waqar and Ghulam Mohy-ud-din improved the theoretical aspects of this paper. All authors revised and approved the manuscript.

Conflicts of Interest: The authors declare no conflict of interest.

\section{Nomenclature}

$V_{\text {se }} \quad$ Series voltage source magnitude

$V_{\text {sh }} \quad$ Shunt voltage source magnitude

$\theta_{\text {sh }} \quad$ Shunt voltage source angle

$\theta_{\text {se }} \quad$ Series Voltage source angle

$P_{k} \quad$ Active power at bus $k$

$S_{l}, S_{\text {lmax }} \quad$ Apparent power in the line $l$ and Maximum apparent power in the line $l$

$V_{m} \quad$ Voltage magnitude at bus $m$

$V_{\text {mref }} \quad$ Reference voltage at bus $m$

$p \& q \quad$ Coefficients to compensate more or less the overloaded transmission lines and voltage variations of buses (Proposed value is 2 in our objective function)

$w_{l} \& w_{m} \quad$ Weight coefficients and have index values for $10 \%$ voltage difference and $100 \%$ branch

loading in this case

$P_{k} \& P_{m} \quad$ Active powers at bus $k$ and bus $m$ terminal respectively

$Q_{k} \& Q_{m} \quad$ Reactive powers at bus $k$ and bus $m$ respectively

$P_{d k} \& Q_{d k} \quad$ Active and reactive power loads at bus $k$

$P_{d m} \& Q_{d m} \quad$ Active and reactive power demands at bus $m$ respectively

$n_{b} \& n_{t l} \quad$ Number of buses and number of transmission lines

$V_{k} \& V_{m} \quad$ Voltage magnitudes at bus $k$ and $m$

$\theta_{k} \& \theta_{m} \quad$ Angles at bus $k$ and $m$ 


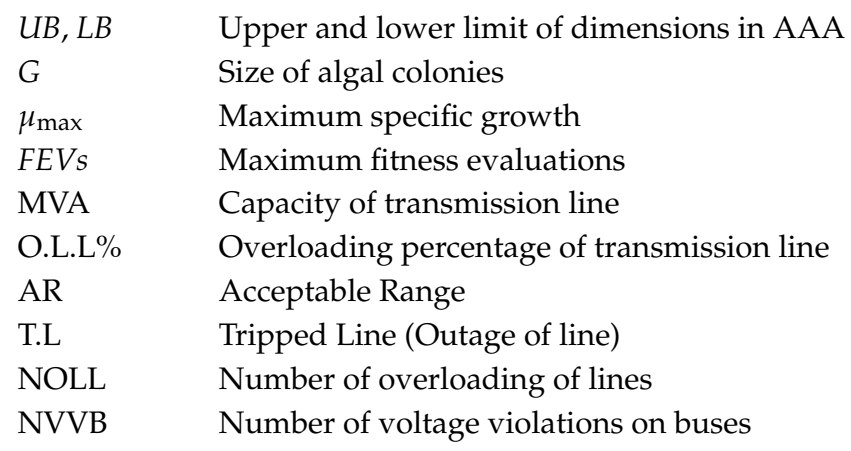

\section{References}

1. Shaheen, H.I.; Rashed, G.I.; Cheng, S.J. Optimal location and parameter setting of UPFC for enhancing power system security based on differential evolution algorithm. Int. J. Electr. Power Energy Syst. 2011, 33, 94-105. [CrossRef]

2. Hingorani, N.G.; Gyugyi, L.; Mohmed, E.1.H.M. Understanding FACTS: Concepts and Technology of Flexible AC Transmission Systems; IEEE Press: New York, NY, USA, 2000; Volume 2.

3. Gyugyi, L. Unified power-flow control concept for flexible AC transmission systems. IEE Proc. C 1992, 139, 323-331. [CrossRef]

4. Fuerte-Esquivel, C.R.; Enrique, A. A Newton-type algorithm for the control of power flow in electrical power networks. IEEE Trans. Power Syst. 1997, 12, 1474-1480. [CrossRef]

5. Ejebe, G.C.; Wollenberg, B.F. Automatic contingency selection. IEEE Trans. Power Appar. Syst. 1979, PAS-98, 97-109. [CrossRef]

6. Mikolinnas, T.A.; Wollenberg, B.F. An advanced contingency selection algorithm. IEEE Trans. Power Appar. Syst 1981, PAS-100, 608-617. [CrossRef]

7. Sobajic, D.J.; Pao, Y.H. An artificial intelligence system for power system contingency screening. IEEE Trans. Power Syst. 1988, 3, 647-653. [CrossRef]

8. Shaheen, H.I.; Rashed, G.I.; Cheng, S.J. Optimal location and parameters setting of UPFC based on GA and PSO for enhancing power system security under single contingencies. In Proceedings of the IEEE Power and Energy Society General Meeting-Conversion and Delivery of Electrical Energy, Pittsburgh, PA, USA, 20-24 July 2008; pp. 1-8.

9. Shaheen, H.I.; Rashed, G.I.; Cheng, S.J. Application and comparison of computational intelligence techniques for optimal location and parameter setting of UPFC. Eng. Appl. Artif. Intell. 2010, 23, 203-216. [CrossRef]

10. Kumar, G.N.; Kalavathi, M.S. Cat swarm optimization for optimal placement of multiple UPFC's in voltage stability enhancement under contingency. Int. J. Electr. Power Energy Syst. 2014, 57, 97-104. [CrossRef]

11. Hagh, M.T.; Alipour, M.; Teimourzadeh, S. Application of HGSO to security based optimal placement and parameter setting of UPFC. Energy Conv. Manag. 2014, 86, 873-885. [CrossRef]

12. Sarker, J.; Goswami, S.K. Solution of multiple UPFC placement problems using Gravitational Search Algorithm. Int. J. Electr. Power Energy Syst. 2014, 55, 531-541. [CrossRef]

13. Jordehi, A.R. Brainstorm optimization algorithm (BSOA): An efficient algorithm for finding optimal location and setting of FACTS devices in electric power systems. Int. J. Electr. Power Energy Syst. 2015, 69, 48-57. [CrossRef]

14. Taher, S.A.; Amooshahi, M.K. New approach for optimal UPFC placement using hybrid immune algorithm in electric power systems. Int. J. Electr. Power Energy Syst. 2012, 43, 899-909. [CrossRef]

15. Mukherjee, A.; Mukherjee, V. Solution of optimal power flow with FACTS devices using a novel oppositional krill herd algorithm. Int. J. Electr. Power Energy Syst. 2016, 78, 700-714. [CrossRef]

16. Moazzami, M.; Morshed, M.J.; Fekih, A. A new optimal unified power flow controller placement and load shedding coordination approach using the Hybrid Imperialist Competitive Algorithm-Pattern Search method for voltage collapse prevention in power system. Int. J. Electr. Power Energy Syst. 2016, 79, 263-274. [CrossRef]

17. Kumar, B.V.; Srikanth, N.V. Optimal location and sizing of Unified Power Flow Controller (UPFC) to improve dynamic stability: A hybrid technique. Int. J. Electr. Power Energy Syst. 2015, 64, 429-438. [CrossRef] 
18. Nireekshana, T.; Rao, G.K.; Raju, S.S. Enhancement of ATC with FACTS devices using real-code genetic algorithm. Int. J. Electr. Power Energy Syst. 2012, 43, 1276-1284. [CrossRef]

19. Phadke, A.R.; Fozdar, M.; Niazi, K.R. A new multi-objective fuzzy-GA formulation for optimal placement and sizing of shunt FACTS controller. Int. J. Electr. Power Energy Syst. 2012, 40, 46-53. [CrossRef]

20. Rao, B.V.; Kumar, G.N. Optimal power flow by BAT search algorithm for generation reallocation with unified power flow controller. Int. J. Electr. Power Energy Syst. 2015, 68, 81-88.

21. Taher, S.A.; Afsari, S.A. Optimal location and sizing of DSTATCOM in distribution systems by immune algorithm. Int. J. Electr. Power Energy Syst. 2014, 60, 34-44. [CrossRef]

22. Alamelu, S.; Baskar, S.; Babulal, C.K.; Jeyadevi, S. Optimal siting and sizing of UPFC using evolutionary algorithms. Int. J. Electr. Power Energy Syst. 2015, 69, 222-231. [CrossRef]

23. Kumar, B.V.; Srikanth, N.V. A hybrid approach for optimal location and capacity of UPFC to improve the dynamic stability of the power system. Appl. Soft Comp. 2017, 52, 974-986. [CrossRef]

24. Mori, H.; Maeda, Y. A hybrid meta-heuristic method for optimal allocation of UPFCs. In Proceedings of the IEEE International Symposium on Circuits and Systems (ISCAS), Taipei, Taiwan, 24-27 May 2009.

25. Uymaz, S.A.; Tezel, G.; Yel, E. Artificial algae algorithm (AAA) for nonlinear global optimization. Appl. Soft Compt. 2015, 31, 153-171. [CrossRef]

26. Acha, E.; Fuerte-Esquivel, C.R.; Ambriz, P.H.; Angeles, C.C. FACTS: Modelling and Simulation in Power Networks; John Wiley \& Sons: Chichester, UK, 2004.

27. Fuerte, E.C.R.; Acha, E.; Ambriz, P.H. A comprehensive Newton-Raphson UPFC model for the quadratic power flow solution of practical power networks. IEEE Trans. Power Syst. 2000, 15, 102-109. [CrossRef]

28. Kothari, D.P.; Nagrath, I.J. Modern Power System Analysis, 3rd ed.; Tata McGraw-Hill Education: New York, NY, USA, 2011.

29. Radu, D.; Besanger, Y. Blackout prevention by optimal insertion of FACTS devices in power systems. In Proceedings of the 2005 International Conference on Future Power Systems, Amsterdam, The Netherlands, 16-18 November 2005.

30. Uymaz, S.A.; Tezel, G.; Yel, E. Artificial algae algorithm with multi-light source for numerical optimization and applications. Biosystems 2015, 138, 25-38. [CrossRef] [PubMed]

31. Expósito, A.G.; Gomez, E.A.; Conejo, A.J.; Canizares, C. Electric Energy Systems: Analysis and Operation; CRC Press: Boca Raton, FL, USA, 2016.

32. Mohy-ud-din, G. Hybrid dynamic economic emission dispatch of thermal, wind, and photovoltaic power using the hybrid backtracking search algorithm with sequential quadratic programming. J. Renew. Sustain. Energy 2017. [CrossRef]

33. Freris, L.L.; Sasson, A.M. Investigation of the load-flow problem. Proc. Inst. Electr. Eng. 1968, 115, 1459-1470. [CrossRef]

(C) 2017 by the authors. Licensee MDPI, Basel, Switzerland. This article is an open access article distributed under the terms and conditions of the Creative Commons Attribution (CC BY) license (http://creativecommons.org/licenses/by/4.0/). 